NBER WORKING PAPER SERIES

\title{
STATE-DEPENDENT OR TIME-DEPENDENT PRICING: DOES IT MATTER FOR RECENT U.S. INFLATION?
}

\author{
Peter J. Klenow \\ Oleksiy Kryvtsov \\ Working Paper 11043 \\ http://www.nber.org/papers/w11043
NATIONAL BUREAU OF ECONOMIC RESEARCH 1050 Massachusetts Avenue
Cambridge, MA 02138
January 2005

\begin{abstract}
We are indebted to Ben Malin for superlative research assistance. We are grateful to John Greenlees, David Johnson, Walter Lane and Teague Ruder of the U.S. Bureau of Labor Statistics for help obtaining the data and invaluable comments. We thank Hoyt Bleakley, Jeff Campbell, V.V. Chari, Michael Dotsey, Jonas Fisher, Mike Golosov, Pat Kehoe, Bob Lucas, Alexander Wolman, and numerous seminar participants for helpful comments. The views expressed in this paper are those of the authors. No responsibility for them should be attributed to the Bank of Canada. Send comments and questions to Pete@Klenow.com and okryvtsov@bankofcanada.ca. The views expressed herein are those of the author(s) and do not necessarily reflect the views of the National Bureau of Economic Research.
\end{abstract}

(C) 2005 by Peter J. Klenow and Oleksiy Kryvtsov. All rights reserved. Short sections of text, not to exceed two paragraphs, may be quoted without explicit permission provided that full credit, including $\odot$ notice, is given to the source. 
State-Dependent or Time-Dependent Pricing: Does it Matter for Recent U.S. Inflation?

Peter J. Klenow and Oleksiy Kryvtsov

NBER Working Paper No. 11043

January 2005

JEL No. E31, E32

\begin{abstract}
Inflation equals the product of two terms: an extensive margin (the fraction of items with price changes) and an intensive margin (the average size of those price changes). The variance of inflation over time can be decomposed into contributions from each margin. The extensive margin figures importantly in many state-dependent pricing models, whereas the intensive margin is the sole source of inflation changes in staggered time-dependent pricing models. We use micro data collected by the U.S. Bureau of Labor Statistics to decompose the variance of consumer price inflation from 1988 through 2003. We find that around $95 \%$ of the variance of monthly inflation stems from fluctuations in the average size of price changes, i.e., the intensive margin. When we calibrate a prominent statedependent pricing model to match this empirical variance decomposition, the model's shock responses are very close to those in time-dependent pricing models.
\end{abstract}

Peter J. Klenow Department of Economics

579 Serra Mall

Stanford University

Stanford, CA 94305-6072

and NBER

Oleksiy Kryvtsov

Bank of Canada

oryvtsov@bankofcanada.ca 


\section{Introduction}

In time-dependent sticky price models, the timing of individual price changes is exogenous. In particular, a firm might set its price every $n$th period (Taylor, 1980) or randomly (Calvo, 1983). The Taylor and Calvo models feature exogenous staggering of price changes across firms in the economy. As a result of this staggering, the fraction of firms adjusting their prices is constant from period to period.

Exogenous and staggered timing allows for tractable aggregation of individual pricing policies and easy solution of dynamic aggregate responses to monetary disturbances. Timedependent models lack microeconomic foundations, however, in contrast to state-dependent pricing models in which firms choose when to change prices subject to "menu costs." The implications of state-dependent models for real output and inflation can differ dramatically from the predictions of traditional time-dependent models. Caplin and Spulber (1987) consider a model of endogenous price adjustment in which, under certain assumptions on the money process and distribution of prices, money has no real effects. Subsequent research by Caballero and Engel $(1993)$ and Caplin and Leahy $(1991,1997)$ examine more general money processes and include sources of heterogeneity across firms. While the Caplin and Spulber neutrality result was not robust to these generalizations, the literature continued to emphasize how state-dependent pricing (SDP) models differ from time-dependent pricing (TDP) models.

Dotsey, King and Wolman (1999) — hereafter DKW — present a general equilibrium model with i.i.d. menu costs. Because the menu costs are i.i.d. across firms at a point in time and across time for a given firm, the state space is manageable. For their chosen parameter values, DKW find that the fraction of firms changing prices responds importantly to monetary shocks. A positive (negative) monetary shock induces more (fewer) firms to change their 
prices. And when more firms adjust their prices, the average size of adjustment is larger. The endogenous bunching of price changes significantly speeds up price adjustment and dampens the short run effects on real output. DKW conclude:

"... the extent of price stickiness and the extent of nonneutrality is very responsive to the nature of agents' beliefs about the permanence of monetary disturbances, because these beliefs affect the incentives that agents have to adjust the timing pattern of their price adjustments. From the perspective of our model then, time-dependent models have been appropriately criticized for treating the pattern of price adjustment as exogenous." (p. 688)

More recent research on SDP models uses newly-available nonlinear solution methods to investigate the implications of persistent menu cost shocks (Willis, 2000), sticky plans (Burstein, 2002), and idiosyncratic marginal cost shocks (Golosov and Lucas, 2003). Like DKW, these studies stress how and when SDP models differ from traditional TDP models because of endogenous timing of price changes.

In this paper we look for bunching of price changes in the data underlying the Consumer Price Index (CPI) compiled by the U.S. Bureau of Labor Statistics (BLS). The data consist of monthly retail prices of individual good and services in the CPI (excluding shelter) from January 1988 through December 2003. Over this period, the 12-month nonshelter inflation rate dipped as low as $-0.2 \%$ and reached as high as $6.4 \%$. To summarize the extent to which price changes are synchronized in the data, we take advantage of an inflation identity. Aggregate inflation in a given month equals the product of two terms: the fraction of items changing price (the extensive margin), and the average size of price changes (the intensive margin). Using this identity, the variance of inflation over time can be decomposed into contributions from each margin. When we implement this decomposition in the 19882003 CPI sample, we find that roughly $95 \%$ of the variance of monthly inflation is due to the 
intensive margin, i.e., "the TDP term." In TDP models, the fraction of items changing price is constant over time, so the TDP term is responsible for $100 \%$ of the variance of inflation. The remaining terms are "SDP terms" in that they involve variation over time in the fraction of items changing price (the extensive margin). In our sample, these SDP terms account for only $5 \%$ or so of the variance of inflation.

We next calibrate the DKW model to match our observed 95-5 variance decomposition. The resulting impulse responses for real output and the price level in this SDP model are very close to those generated under a Calvo TDP model. These results cast doubt on the empirical relevance of those SDP models that feature large fluctuations in the extensive margin, at least for inflation regimes such as the U.S. since 1988.

We organize the rest of the paper as follows. In section 2 we describe the U.S. CPI micro data in detail. We provide variance decompositions based on this data in section 3 . In section 4 we calibrate DKW's state-dependent pricing model to our evidence, and compare the resulting aggregate predictions to those of the Calvo time-dependent pricing model. We offer concluding remarks in section 5 .

\section{BLS Micro Data on Consumer Prices}

To construct the non-shelter portion of the CPI, the BLS surveys the prices of about 85,000 items a month in its Commodities and Services Survey. ${ }^{1}$ Individual prices are collected by 400 or so BLS employees visiting 20,000 retail outlets a month, mainly across 45 large urban areas. The outlets consist of grocery stores, department stores, auto

\footnotetext{
${ }^{1}$ The BLS conducts a separate survey of landlords and homeowners for the shelter portion of the CPI. The sources for this section are the BLS Handbook of Methods (U.S. Department of Labor, 1997, Chapter 17) and unpublished documentation for the CPI-RDB (to be described shortly).
} 
dealerships, hospitals, etc. The survey covers all goods and services other than shelter, or about $70 \%$ of the CPI based on BLS consumer expenditure weights.

The BLS selects outlets and items based on household point-of-purchase surveys, which furnish data on where consumers purchase commodities and services. The Census agents have detailed checklists describing each item to be priced - its outlet and unique identifying characteristics. The agents price each item for up to five years, after which the item is rotated out of the sample.

The CPI Research Database, maintained by the BLS Division of Price and Index Number Research and hereafter denoted CPI-RDB, contains all prices in the Commodities and Services Survey from January 1988 through December 2003. As we now describe, we restrict our attention to a subset of the sample that is best suited to our investigation.

\section{Frequency of BLS Pricing}

The BLS collects consumer prices monthly for food and fuel items in all areas. The BLS also collects prices monthly for all items in the three largest metropolitan areas (New York, Los Angeles, and Chicago). The BLS collects prices for items in other categories and other urban areas only bimonthly. ${ }^{2}$ About $72 \%$ of observations in our pooled sample over the 1988-2003 period are monthly price quotes, and the remaining $28 \%$ are bimonthly. We concentrate our analysis on monthly items. Because our focus is on the endogenous timing of price changes, we prefer a longer sample of 191 monthly observations to a pair of broader samples with bi-monthly observations. We will, however, report some critical statistics for two bi-monthly samples that use price quotes for all items from all urban areas.

\footnotetext{
${ }^{2}$ In Philadelphia and San Francisco the BLS priced items monthly through 1997 and bimonthly thereafter.
} 


\section{Temporary price discounts ("sales")}

According to the BLS, a "sale" price is (a) temporarily lower than the "regular" price, (b) available to all consumers, and (c) usually identified by a sign or statement on the price tag. Roughly $11 \%$ of quotes in the sample are sale prices. Sales are especially frequent for food items, where they comprise $15 \%$ of all quotes (vs. $8 \%$ of non-food price quotes). Chevalier, Kashyap and Rossi (2003) also observe frequent sales in their analysis of scanner data from grocery stores. They report that sales often generate V-shapes, as the price goes down and then returns to the regular (pre-sale) level in the next period. In the BLS data, about two-thirds of sales exhibit this pattern. As a result, we will report statistics for all prices and, separately, for regular prices. When the BLS price is a sale price, we set the unobserved regular price equal to the last observed regular price. We illustrate this in Figure 1.

Figure 2 presents the distribution of times between regular price changes in the Top 3 areas. We use unpublished BLS item weights to calculate the fraction of the total CPI weight represented by prices which last each duration. The more frequently prices change for an item of a given weight, the less weight on each price change. In this way we avoid overweighting frequent short price spells. Still, according to Figure 2, almost half of all regular price changes are separated by a quarter or less. ${ }^{3}$ This reinforces our desire to focus on the monthly price data. The right portion of Figure 2 indicates that only about $10 \%$ of prices last longer than two years.

Figure 3 provides hazard rates, i.e., fractions of prices of each "age" that change. The declining empirical hazard contrasts with the popular Calvo constant hazard formulation,

\footnotetext{
${ }^{3}$ The median time between regular price changes is around 3.8 months. Including sale-related price changes, the median time is 3 months, and it is 4.3 months adjusting for left- and right-censoring of spells. Bils and Klenow (2004) arrive at the same estimate of 4.3 months using the median frequency of price changes across categories.
} 
although the decline could simply reflect a mix of heterogeneous hazards. Consistent with this interpretation, the hazards flatten out when we split items into the most flexible vs. the least flexible. Disaggregating further into 250 or so product categories, the only consistent deviation from a flat hazard is a spike at 12 months. Still, the data do not suggest a singleduration Taylor formulation, much less one as long as a year. ${ }^{4}$

Figure 4 shows that both large and small price changes are common, as are both price increases and price decreases. Around $40 \%$ of regular price changes are smaller than $5 \%$ in absolute value, $28 \%$ are smaller than $2.5 \%$, and $14 \%$ are smaller than $1 \%$. The existence of many large and small price changes is consistent with a wide range of menu costs across items and/or time, as in the DKW model.

\section{Forced Item substitutions}

Forced item substitutions occur when the item has been discontinued from the outlet and the Census agent identifies a similar replacement item in the outlet to price going forward. This often takes the form of a product upgrade or model changeover. The monthly rate of forced item substitutions hovers around 3\% in the sample. Essentially all item substitutions involve price changes. Because it is not clear whether price changes associated with product turnover are what modelers of sticky prices have in mind (e.g., they might entail smaller or larger menu costs), we calculate all statistics with and without item substitutions.

\section{Out-of-season items}

Although the Commodities and Services Survey attempts to price 85,000 or so items per month, the field agents succeed in collecting around 74,000 price quotes in the typical

\footnotetext{
${ }^{4}$ Campbell and Eden (2004) find declining hazards in weekly scanner data for a number of grocery store items. Across identical products at different stores, they find hazards rising sharply only for prices far from the mean.
} 
month. The 11,000 unavailable quotes per month consist of out-of-season items, temporary stockouts, and permanently discontinued items. The BLS categorizes about $5 \%$ of the items they attempt to price as out-of-season in the average month. The out-of-season fraction is, not surprisingly, particularly high for clothes. As Figure 1 demonstrates, we include price changes across missing observations. We do this because it turns out to be important for getting close to the mean inflation rate for the official CPI. None of our inflation decomposition results are sensitive to (instead) including only adjacent price quotes when calculating price changes.

\section{Stockouts}

Even when in season, almost $7 \%$ of items are temporarily unavailable in a typical month. The BLS reserves this classification for items that are temporarily out of stock from the outlet or at outlets that are temporarily closed. In our calculations, we treat out-of-stock items as we do seasonally unavailable items (see Figure 1).

\section{Outliers}

Although the BLS requires the collection agents to explain large price changes to limit measurement errors, some price changes in the dataset appear implausibly large. We exclude price changes that exceed a factor of 10. Such price jumps constitute less than one tenth of one percent of all price changes.

\section{Summary Statistics}

With our sampling decisions, we arrive at a subset of the CPI-RDB consisting of about 55,000 price quotes a month. Let $p_{i t}$ represent the $\log$ price of item $i$ in month $t$, and let $\omega_{i t}$ 
represent the CPI weight of item $i$ in month $t . I_{i t}$ denotes an indicator of a price change for item $i$ in month $t$ :

$$
I_{i t}=\left\{\begin{array}{lll}
1 & \text { if } & p_{i t} \neq p_{i t-1} \\
0 & \text { if } & p_{i t}=p_{i t-1}
\end{array}\right.
$$

We exploit the following identity for aggregate monthly inflation, $\pi_{t}$ :

$$
\pi_{t} \triangleq \sum_{i} \omega_{i t}\left(p_{i t}-p_{i t-1}\right)=\underbrace{\sum_{i} \omega_{i t} I_{i t}}_{f r_{t}} \cdot \underbrace{\frac{\sum_{i} \omega_{i t}\left(p_{i t}-p_{i t-1}\right)}{\sum_{i} \omega_{i t} I_{i t}}}_{d p_{t}}
$$

As shown, $f r_{t}$ is the "fraction" (more accurately, the CPI weight) of items changing price in month $t$, and $d p_{t}$ is the weighted-average magnitude of price changes occurring in month $t$. In words, aggregate inflation is the product of the fraction of items with price changes (the extensive margin) and the average size of those price changes (the intensive margin). We use geometric weights in (1). The BLS began using geometric weights within categories of consumption in 1999.

Figures 5 and 6 plot $f r_{t}$ and $d p_{t}$, respectively, for the Top 3 areas from February 1988 through December 2003. The fraction of items changing price fluctuates mostly between $25 \%$ and $35 \%$ across months. The average size of price changes usually falls between $-2 \%$ and $+3 \%$. Perhaps more revealing is Figure 7 , which displays 12 -month moving averages for $\pi_{t}, f r_{t}$ and $d p_{t}$. The extensive margin ( $\left.f r_{t}\right)$ is relatively stable and not so obviously 
correlated with inflation, whereas the intensive margin $\left(d p_{t}\right)$ is volatile and obviously correlated with inflation. ${ }^{5}$

Table 1 contains summary statistics for four samples, each for the Top 3 Areas (New York, Los Angeles and Chicago): all prices for all items, regular prices for all items, all prices for core items, and regular prices for core items. Core items are those other than food and energy. The first entry in Table 1 gives average monthly inflation as $0.19 \%$ per month from February 1988 through December of $2003 .^{6}$ The 12 -month inflation rate ranges from $-0.5 \%$ to $5.9 \%$ across the sample, as depicted in Figure 7 . The fraction of items changing price in the Top 3 areas averages 29\% a month, 26\% when sales are excluded. This high frequency of price changes is in line with the findings of Bils and Klenow (2004). The results for core items are similar, as shown in Table 1. For all samples, the across-months standard deviation in the fraction of items changing price is around $3 \%$.

We noted earlier that $11 \%$ of quotes were "sale" prices. Yet in Table 1 the mean fr is only $6 \%$ points lower for regular prices than for all prices. The reason is that categories with a larger share of sale prices happen to have smaller weight in consumer expenditures. For example, $40 \%$ of all food price changes are sales-related and food price quotes constitute $39 \%$ of all price quotes, yet food items constitute only $10 \%$ of consumer expenditures.

In Table 1 we also report the fraction of items increasing in price $(f r+)$ and the fraction decreasing in price $(f r-)$, which sum to the fraction changing price $(f r) .45 \%$ of price changes are negative. The fraction is $42 \%$ for regular price changes, so price declines do not simply

\footnotetext{
${ }^{5}$ Our Top 3 Area non-shelter inflation series displayed in Figure 7 is not the same as the overall CPI inflation series, which covers all areas and includes shelter.

${ }^{6}$ The annual rate is $2.2 \%$. By comparison, the average non-shelter inflation rate across all CPI areas was $2.7 \%$ over the same period. The difference appears to reflect our use of geometric weights in (1) rather than our focus on the Top 3 areas.
} 
reflect temporary price discounts. Related, the last column in Table 1 shows that the average absolute price change is over 13\% in the Top 3 areas. Even regular price changes are large, averaging over $8 \%$. The combination of small average price changes and large average absolute price changes suggests substantial idiosyncratic shocks to marginal cost or desired markups. Golosov and Lucas (2003) use this evidence to motivate a state-dependent pricing model with idiosyncratic productivity shocks. ${ }^{7}$

\section{Decomposing the Variance of Inflation}

In this section we decompose the variance of inflation over time into (terms involving) the variance of the average magnitude of price changes, the variance of the fraction of items changing price, and the covariance between the two. For this purpose, it is convenient to expand (1) into

$$
\pi_{t}=f r_{t} \cdot d p_{t}=\overline{f r} \cdot d p_{t}+f r_{t} \cdot \overline{d p}+\left(d p_{t}-\overline{d p}\right) \cdot\left(f r_{t}-\overline{f r}\right)-\overline{f r} \cdot \overline{d p}
$$

where $\overline{f r}$ and $\overline{d p}$ represent sample means. Using (2), we obtain the following variance decomposition:

$$
\operatorname{var}\left(\pi_{t}\right)=\underbrace{\overline{f r}^{2} \cdot \operatorname{var}\left(d p_{t}\right)}_{\text {TDPterm }}+\underbrace{\operatorname{var}\left(f r_{t} \cdot \overline{d p}+\left(d p_{t}-\overline{d p}\right) \cdot\left(f r_{t}-\overline{f r}\right)\right)+2 \operatorname{cov}_{t}}_{\text {SDPterms }}
$$

\footnotetext{
${ }^{7}$ In an attached Appendix, we briefly describe five moments we calculated from the $C P I-R D B$ expressly for Golosov and Lucas (2003).
} 
where $\operatorname{cov}_{t}=\operatorname{cov}\left(\overline{f r} \cdot d p_{t}, f r_{t} \cdot \overline{d p}+\left(d p_{t}-\overline{d p}\right) \cdot\left(f r_{t}-\overline{f r}\right)\right)$. For conveying intuition, we find it useful to take the variance of a first-order Taylor series expansion of $\pi_{t}=f r_{t} \cdot d p_{t}$ around the sample means $\overline{f r}$ and $\overline{d p}$ to arrive at an alternative (but also exact) variance decomposition:

$$
\operatorname{var}\left(\pi_{t}\right)=\underbrace{\operatorname{var}\left(d p_{t}\right) \cdot \overline{f r}^{2}}_{\text {TDP term }}+\underbrace{\operatorname{var}\left(f r_{t}\right) \cdot \overline{d p}^{2}+2 \cdot \overline{f r} \cdot \overline{d p} \cdot \operatorname{cov}\left(f r_{t}, d p_{t}\right)+O_{t}}_{S D P \text { terms }} .
$$

Expression (4) more closely resembles the familiar decomposition of the variance of a sum of two variables. The higher order terms $\left(O_{t}\right)$ and even the covariance term turn out to be small both in the data and in the state-dependent models we simulate. The quantitatively important terms are the respective variance terms.

Tables 2 and 3 report variance decompositions based on all prices and regular prices, respectively. Within each Table, we present results with and without item substitutions in separate columns. The rows of each Table present results for three urban areas, and separately for core items. We present the "TDP term" and the sum of the "SDP terms" from (3). The TDP term captures changes in the intensive margin, which account for all of the variation in inflation in staggered TDP models. The SDP terms involve changes in the extensive margin, which only contribute in SDP models.

The results in Tables 2 and 3 are striking. The intensive margin (the TDP term) accounts for between $88 \%$ and $111 \%$ of inflation's variance across the 20 permutations. In 16 of the 20 cases, the TDP term accounts for between $91 \%$ and $102 \%$ of inflation's variance. We summarize by saying the TDP term accounts for roughly $95 \%$ of the variance of inflation in this data. Fluctuations in the fraction of items changing price - a key endogenous variable 
in many SDP models - are a relatively unimportant source of fluctuations in inflation. As shown in Tables 2 and 3, this result is robust to excluding both substitution-related price changes and sale-related price changes, holds for the three urban areas individually as well as collectively, and applies to core items as well as all items. ${ }^{8}$

Although our focus is the monthly data, we checked the robustness of our findings to aggregation over time and to inclusion of urban areas with bi-monthly price quotes. First, we calculated variance decompositions for 95-observation "odd" and "even" bi-monthly samples for the Top 3 urban areas. Across the samples (all prices vs. regular prices, with vs. without substitutions), the TDP term accounted for between $86 \%$ and $113 \%$ of the variance of bimonthly inflation. Second, we constructed a 63-quarter sample for the Top 3 areas. Here the TDP term represented between $91 \%$ and $97 \%$ of inflation's variance. Finally and most important, we looked at bi-monthly inflation for all urban areas rather than just areas with monthly price quotes. Bi-monthly price quotes are on odd and even cycles, so we constructed an odd and an even bi-monthly inflation rate - again for all urban areas in the CPI. Across the odd and even samples, the TDP term accounted for between $87 \%$ and $99 \%$ of inflation's variance. In sum, variation in the size of price changes explains the bulk of inflation's variance at the bi-monthly and quarterly frequency and across all urban areas, not just at the monthly frequency in Top 3 Areas.

Table 4 contains across-time correlations between the monthly variables $\pi$, $f r$, and $d p$. Consistent with the variance decompositions, the average size of price adjustments $(d p)$ comoves almost perfectly with inflation. The correlation is 0.98 or higher across the samples.

\footnotetext{
${ }^{8}$ Cecchetti (1985) points out that, if price changes are perfectly staggered, then one can estimate the frequency of price changes from across-good variation of inflation relative to mean inflation. He successfully applies this to magazine prices, meaning their changes are indeed largely staggered - a precursor to our finding. In Cecchetti (1987), he applies the same methodology to estimate the frequency of wage changes.
} 
The correlation between the average fraction of items changing price $(f r)$ and inflation is markedly lower at around 0.3 .

The correlation between the size $(d p)$ and fraction ( $f r)$ of price changes in the Top 3 areas is positive but modest in all samples, at most 0.3 . This evidence will contrast with the DKW model, which implies strong positive comovement between the size and incidence of price changes. In the DKW model, the need for larger price changes (the intensive margin) induces firms with larger menu costs to accelerate price changes (the extensive margin) after positive shocks. We illustrate this in the next section.

\section{Implications for Sticky-Price Models}

In this section we demonstrate some implications for popular sticky price models of the facts we presented in Tables 1 through 4. In particular, we will use the DKW model (Dotsey, King and Wolman, 1999). It is a tractable dynamic stochastic general equilibrium model in which firms face fixed costs of price adjustment which are i.i.d. across firms and across time. When the size of aggregate disturbances is small, the equilibrium in this model can be well-mimicked by a log-linear approximation around a stationary steady state.

In the following subsection we briefly describe the DKW model and then discuss its predictions for business cycle dynamics under the parameter values used by DKW. We next calibrate the model to fit the empirical evidence presented in section 3 . We will show that these two economies have very different responses to aggregate shocks.

\section{The DKW model}

We adhere as closely as possible to the baseline specification of Dotsey, King and Wolman (1999), i.e., DKW. The economy is populated with a continuum of identical 
households. Each household purchases bundle $\left\{c_{i t}\right\}$ of differentiated consumption goods in period $t$, where $i$ spans the fixed variety of goods. Households supply labor $l_{t}$ and hold real money balances $m_{t}$. Current period utility is

$$
U\left(c_{t}, l_{t}, m_{t}\right)=\frac{1}{1-\sigma}\left[\left(\omega c_{t}^{\frac{\eta-1}{\eta}}+(1-\omega) m_{t}^{\frac{\eta-1}{\eta}}\right)^{\frac{\eta}{1-\eta}}\right]^{1-\sigma}+\frac{\psi\left(1-l_{t}\right)^{1-\xi}}{1-\xi}
$$

where $\sigma$ is the risk aversion parameter, $\omega$ is a weight on consumption vs. money holdings, $\eta$ is the interest elasticity of money demand, $\psi$ is the weight on leisure, $\xi$ is the labor supply parameter, and $c_{t}$ is the Dixit-Stiglitz aggregate consumption index

$$
c_{t}=\left[\int_{0}^{1} c_{i t}^{\theta} d i\right]^{1 / \theta} .
$$

Monopolistically competitive firms hire capital $\left(k_{i t}\right)$ and labor $\left(l_{i t}\right)$ in competitive markets to produce a variety $i$ consumption good subject to a Cobb-Douglas production technology:

$$
y_{i t}=e^{a_{t}} k_{i t}^{\alpha} l_{i t}^{1-\alpha}
$$

where $a_{t}$ is an aggregate productivity index. We assume $a_{t}$ follows a random walk with drift:

$$
a_{t}=\mu_{a}+a_{t-1}+\varepsilon_{a t}
$$

where $\varepsilon_{a t}$ is a zero mean, normally distributed error with standard deviation $\sigma_{a}{ }^{9}$ For simplicity the aggregate capital stock is fixed but capital is perfectly mobile across firms.

\footnotetext{
${ }^{9}$ We added a productivity shock to DKW's specification because we will calibrate their model to fit facts about inflation, the intensive margin, and the extensive margin.
} 
Each firm faces a fixed cost of adjusting its price. These menu costs are i.i.d. across firms and over time. The menu costs are drawn from a differentiable, four-parameter c.d.f.

$$
G(\xi)=c_{1}+c_{2} \tan \left(c_{3} \cdot \xi-c_{4}\right), \quad \xi \in\left[\xi_{\min }, \xi_{\max }\right]
$$

with properties $\xi_{\min } \geq 0, G\left(\xi_{\min }\right)=0, \xi_{\max }<\infty, G\left(\xi_{\max }\right)=1$.

The price set by adjusting firms is equal to the present discounted value of future nominal marginal costs weighted by the unconditional probability of the price remaining in effect in each period. Since firms are ex ante identical with respect to the menu costs they will face, adjusting firms assign the same probabilities to changing their price in each future period. Firms operate the same production technology and face the same input prices, so they also have the same marginal cost. As a result, all firms adjusting their price in a given period choose the same price.

With positive trend inflation the maximal number of periods $(J)$ the firm is willing to go without changing its price is finite. Each firm will want to adjust after $J$ periods with probability 1 because, for any realization of menu costs $\left(\xi_{\max }<\infty\right)$, the benefit from adjusting (a higher markup) will exceed the benefit from waiting one more period (foregoing the menu cost). Firms will therefore be distributed between $J$ cohorts, with firms choosing the same price and output within each cohort. These features render the state space of the model small, and the model tractable and easy to solve.

The government changes the supply of money in the economy via lump-sum transfers to households. The rate of growth of the money supply follows the AR(1) process

$$
\mu_{t}=\left(1-\rho_{m}\right) \mu_{m}+\rho_{m} \mu_{t-1}+\varepsilon_{m t},
$$


where $\rho_{m}<1, \mu_{m}$ is the mean growth rate of the money supply, and $\varepsilon_{m t}$ is a zero mean, normally distributed error with standard deviation $\sigma_{m}$.

\section{Simulating DKW economies}

An equilibrium is a sequence of prices and allocations such that the optimization problems of households and firms are solved and all markets clear. Following DKW, we implement a log-linear approximation of the equilibrium around the stationary steady state path (the equilibrium with no aggregate shocks, only idiosyncratic menu costs). We simulate equilibrium realizations for three sets of parameter values: the parameter values originally used by DKW (“Original Quarterly”), the monthly versions of the original DKW parameter values (“Original Monthly”), and, finally, parameter values calibrated to the key empirical evidence we presented in Tables 1 through 4 (“Calibrated Monthly”). We very briefly describe these economies in Table 5 and provide their parameter values in Table 6.

Column A of Table 6 contains the original parameter values used by DKW. For this quarterly SDP economy, the top panel of Figure 8 presents responses of output, the price level and the fraction of firms changing prices to a permanent $+1 \%$ impulse in the money supply. These figures accurately mimic those in DKW (1999, Figure IV). Each plot contrasts responses in the SDP economy to those in a TDP economy. The TDP economy is a Calvo economy with a constant probability of a price change until $J=8$ quarters since the last price adjustment, at which point the probability jumps to 1 as in the SDP economy. In each period, the fraction of firms changing prices in the TDP economy equals the unconditional mean fraction in the comparison SDP economy.

In the quarter of the money shock, output increases by about $0.4 \%$ in the SDP economy, compared to about $0.8 \%$ in the TDP economy. Over the next four quarters, output 
returns to its steady state level. The price level rises almost $0.7 \%$ in the SDP economy on impact (vs. only $0.2 \%$ in the TDP economy). The fraction of firms adjusting their prices jumps 7 percentage points when the money supply surges, then falls back to the pre-shock level of $20 \%$ a quarter within a year. All three variables exhibit echo effects eight quarters after the shock, related to the number of cohorts $J=8$. For the first few quarters after the shock, firms are accelerating price changes. This tilts the size of cohorts toward those with younger prices, and results in fewer price adjustments three to seven quarters after the shock. After 8 quarters the firms who sped up price changes in response to the shock have older prices, pushing the hazard rate up again.

To summarize the different dynamic responses of the SDP and TDP economies, we sum their absolute $\%$ response differences. We denote the cumulative absolute response differences for $X$ (real output or the price level) as

$$
C R D_{X}=H \sum_{i=0}^{\infty}\left|X_{i}^{S D P}-X_{i}^{T D P}\right|
$$

where $X_{i}^{S D P}\left(X_{i}^{T D P}\right)$ is the impulse response at the $i$-th lag in the SDP (TDP) economy. To make the responses comparable across quarterly and monthly economies, $H$ is 1 for monthly responses and 3 for quarterly responses. For the Original Quarterly DKW economy in the top panel of Figure 8 , the output responses differ by a cumulative $6.5 \%$ and the price responses by a cumulative $8.3 \%$.

A striking difference between the quarterly SDP and TDP economies can be seen in the variance decompositions they imply for inflation. As shown in Column A of Table 7, in the Original Quarterly DKW economy the "TDP term" accounts for only $20 \%$ of the variance of inflation on average across 100 simulations of 63 quarters. The standard deviation of the 
TDP term across simulations is about $5 \%$ for all simulations. Fluctuations in the fraction of firms changing prices account for $80 \%$ of inflation's variance, with $39 \%$ due to the variance of the fraction adjusting, $36 \%$ coming from the positive covariance between the fraction adjusting and the size of adjustments, and the remaining $5 \%$ due to the higher order terms. In contrast to the empirical 95-5 decomposition (from Tables 2 and 3), the decomposition in the Original Quarterly DKW economy is 20-80; the decomposition in the TDP economy is, of course, $100-0$.

To facilitate comparison to our monthly BLS data, we next simulate a monthly parameterization of the DKW model. For this purpose we adjust the discount rate, the labor endowment, and the standard deviation of monetary shocks appropriately. In addition, we adjust the parameters of the menu cost distribution to obtain a monthly mean fraction of firms changing prices equal to $6.7 \%$. This implies a three-month fraction equal to the $20 \%$ in DKW's quarterly economy. Column B of Table 6 lists the "Original Monthly" parameter values, our monthly translation of DKW's quarterly parameterization.

The bottom panel of Figure 8 shows responses to a permanent, unanticipated 1\% money supply increase for this Original Monthly economy. The responses are qualitatively similar to those in the Original Quarterly economy. Differences between the SDP and TDP monthly economies are smaller because the fraction of firms adjusting prices is lower in a month than in a quarter. As shown in Column B of Table 7, the cumulative absolute response differences are modestly lower for the monthly version (by 0.9 for real output and 1.1 percentage points for the price level). Compared to the steady state fraction of firms adjusting, however, the response in the extensive margin is actually larger in the monthly economy (a $42 \%$ increase above the steady state fraction vs. $35 \%$ in the quarterly economy). 
Comparing Columns A and B of Table 7, we see very similar variance decompositions in the quarterly and monthly versions of DKW's parameterization. For the monthly parameterization the TDP term is $22 \%$ and the SDP terms account for $78 \%$. The roughly 20 80 decompositions in the quarterly and monthly DKW economies contrast starkly with the 955 variance decomposition in the BLS data.

To test whether the discrepancy is due to the higher trend inflation in the DKW parameterization than in the BLS data, we repeated the simulations of the DKW economies setting trend money growth to fit average monthly (regular price) inflation in the Top 3 areas of 3.2\% per year from February 1988 through December 2003. The TDP terms in the variance decomposition did rise to $28 \%$, but this is still far from the empirical $95-5$ decomposition. We next pursue the question of whether a DKW model calibrated to match the empirical 95-5 split exhibits impulse response functions very different from a simple TDP model (a 100-0 split).

Column C of Table 6 lists the parameter values for the "Calibrated Monthly" DKW economy. The parameter values we explicitly calibrate to data are as follows. We set the productivity drift to $1.5 \%$ per year and its monthly standard deviation to $0.4 \%$, consistent with the behavior of quarterly U.S. TFP growth from 1988 through 2002. We then chose trend money growth $\left(\mu_{m}\right)$ and the standard deviation of its innovation $\left(\sigma_{m}\right)$ to fit the mean $(0.26 \%$ per month) and standard deviation ( $0.28 \%)$ of regular price inflation in the Top 3 areas from February 1988 through December 2003. We selected two of the four parameter values of the menu cost distribution to fit the $23 \%$ mean fraction of items changing their regular price and the $95 \%$ TDP term in the variance decomposition for regular price inflation, both for the Top 3 areas over February 1988 through December 2003. We set the final two parameter values 
of the menu cost distribution as follows. We set the minimal menu cost $\left(\xi_{\text {min }}\right)$ to zero because small price changes are common in the micro data. We set the maximal menu cost $\left(\xi_{\max }\right)$ to $0.2 \%$ of the labor endowment, the largest value for which we could also match the $95-5$ decomposition. We chose the largest maximal menu cost possible because we are far below DKW's maximal menu cost of $2.25 \%$.

Figure 9 contrasts the distribution of menu costs in the Original Monthly and Calibrated Monthly DKW economies. The top panel of Figure 9 shows the distribution of menu costs for the Original Monthly economy. For comparison, the cdf of a Calvo TDP economy is shown - a step function dividing unit probability between realizations of either zero or maximal fixed cost. A firm facing a Calvo distribution of menu costs will decide whether to adjust independent of the realization of the aggregate state: when the realized menu cost is zero, the firm will always adjust; conversely, the firm will not adjust until $J$ periods since the last adjustment when the menu cost is prohibitively high. This is not true for a firm facing a smooth cdf, which puts positive probability on menu costs between 0 and $\xi_{\max }$. In this case, a firm facing an intermediate menu cost will adjust only if the aggregate shocks that have accumulated since its last price change are sufficiently large.

The bottom panel of Figure 9 shows the menu cost distribution in our Calibrated DKW economy. It is very close to the step-like cdf in the Calvo TDP model. The probability of intermediate menu costs is much smaller than the probability of extreme ( 0 or $\left.\xi_{\max }\right)$ menu costs. Hence, in the Calibrated DKW economy, most of the time firms will be adjusting (or not) independent of the realization of aggregate shocks.

Figure 10 illustrates responses to money and productivity impulses, respectively, for the Calibrated Monthly DKW economy. The responses of real output and the price level are 
very similar in this economy to those in the TDP economy. The absolute response differences for output and the price level cumulate to $0.1 \%$ or less for both monetary and productivity shocks (see Table 7). These cumulative differences are an order of magnitude smaller than those under DKW parameter values. A menu cost distribution that produces a 95-5 variance decomposition evidently yields impulse response functions quite close to those of a TDP model with its 100-0 decomposition.

As shown in the rightmost plots of Figure 10, firms do alter the timing of their price changes in the Calibrated DKW economy, but the responses are smaller and shorter-lived than under the DKW parameter values. Relative to the steady state fraction, $6 \%$ more firms change prices after a monetary expansion, compared to $42 \%$ after a similar monetary shock under DKW parameter values. The fraction falls back to the steady state level over a few months, rather than persisting for five months or more. In order to match the $95-5$ variance decomposition, firms must have limited incentive to synchronize their price changes in response to aggregate shocks.

Figure 11 features steady state hazard rates and price age distributions in the DKW economies. Consistent with the fixed cost distributions (see Figure 9), hazards are almost flat for the Calibrated DKW economy, and increasing for the Original Monthly DKW economy. The flat hazard rates in the Calibrated DKW economy are in line with those in the micro data for individual items (see the discussion surrounding Figure 3 in section 2). The distribution of firms across price ages in the Calibrated DKW economy has a steeper slope than the distribution in the Original Monthly economy, which also conforms with the micro evidence (see Figure 2). 
Table 8 compares correlations in the two monthly DKW economies to those in the Top 3 areas (regular prices). In each case the Calibrated DKW economy comes closer to the data than the Original Monthly DKW economy. Still, in many cases the discrepancy between the Calibrated economy and the data remains large. A model with persistent shocks to average menu costs, rather than i.i.d. menu costs over time, might come closer to the data. In particular, such shocks might lower the correlation between the fraction and size of price changes, and raise the serial correlation of the fraction. As we will discuss in the conclusion, a more computationally-challenging generalization would be to add firm-specific shocks to marginal cost and/or desired markups.

\section{Robustness}

We now gauge the sensitivity of our results to: 1) the number of cohorts in our comparison TDP economy; 2) the serial correlation of money growth shocks; 3) the elasticity of substitution between goods (the steady state markup); 4) the interest elasticity of money demand; and 5) the labor supply elasticity.

For each TDP economy we entertained a truncated Calvo model in which the probability of a price change jumped to 1 for the final cohort. The number of cohorts $J$ in each TDP economy was set equal to the endogenous $J$ in the corresponding SDP economy. To more closely approximate Calvo's specification, we now try extending the truncation point to 50 months from $J=24$ months. The absolute response differences between this TDP economy and the Calibrated DKW economy remain small: $0.2 \%$ for output and $0.3 \%$ for the price level.

We previously assumed serially uncorrelated money growth. To simulate the Calibrated DKW economy with persistent monetary shocks, we now set the serial correlation 
of monetary shocks equal to 0.83 as in Chari, Kehoe, and McGrattan (2000). Under this recalibration, the differential responses to a persistent money shock cumulate to $0.1 \%$ and $1.3 \%$ for output and prices, respectively. Even with persistent shocks to monetary policy, therefore, impulse responses in the DKW model are close to those in the TDP model. ${ }^{10}$

Finally, we look at a range of plausible values for the preference and markup parameters. We examine a steady state markup $(1 / \theta)$ between $11 \%$ and $50 \%$ (vs. a baseline value of 30\%), an interest elasticity of money demand $(\eta)$ between 0 and 1 (vs. a baseline value of 0 ), and a labor supply elasticity between $-\infty$ and -1.3 (vs. a baseline value of $-\infty$ ). For each parameter value, the cumulative response differences in the re-calibrated SDP and TDP economies changed by less than a tenth of a percentage point.

\section{Simulating a 1970s economy}

A potential criticism of our findings is that inflation was too low and stable in the U.S. from 1988 to 2003 to provide a useful testing ground for SDP models. Over this time period 12-month CPI inflation (excluding shelter) ranged from a maximum of $6.4 \%$ in November 1990 to a minimum of $-0.2 \%$ in February 2002. The mean was $2.7 \%$ and the standard deviation $1.4 \%$.

A natural question to ask is whether the extensive margin would contribute more in a period of higher and more volatile inflation, such as the 1970s in the U.S. While the ultimate answer hinges on the availability of micro data from such periods, here we conduct a counterfactual experiment by re-calibrating the DKW model to U.S. inflation in the 1970s. From January 1970 through December 1979, one-year CPI inflation averaged 6.8\%. It ranged

\footnotetext{
${ }^{10}$ Wolman (1999) showed that Calvo with rising (as opposed to flat) hazards can produce very different impulse responses. We find that cumulative response differences under persistent monetary shocks are insensitive to this distinction because hazard rates in the Calibrated Monthly economy are almost flat (see Figure 11, top panel).
} 
from $2.3 \%$ in June 1972 to $11.8 \%$ in November 1974 and exhibited a standard deviation of 2.6\%. We take the parameter values in Column $\mathrm{C}$ in Table 6 and adjust the trend and standard deviation of money growth so that the model matches the higher mean and standard deviation of monthly CPI inflation in the 1970s. We leave the rest of the parameter values (e.g., the distribution of menu costs) unchanged.

The 1970s DKW economy differs from the 1988-2003 DKW economy as follows. The average fraction of firms changing price is $26 \%$ rather than the $23 \%$ (and $J=8$ rather than 14 months). Firms choose to change prices more frequently in the presence of higher trend money growth. Surprisingly, the standard deviation of the extensive margin is only $0.3 \%$ rather than $2.8 \%$. As a consequence, the TDP term in the variance decomposition is actually higher at $98 \%$ rather than $95 \%$.

Our intuition for this unexpectedly finding is as follows. There are two effects that shape the output and price responses to, for instance, a monetary shock. First, higher average inflation implies a higher average fraction of firms adjusting prices. Since firms that adjust in the period of the shock contribute least to the change in output, the initial output response is smaller. Second, firms have less incentive to accelerate or postpone their price changes because the average time between price changes is smaller. This latter effect increases the output response, so that the overall impact of a monetary shock on output can be bigger or smaller when average inflation is higher. This ambiguous effect of higher trend inflation on the output effect of a monetary shock was also emphasized by Dotsey, King and Wolman (1999, page 685).

More important for our investigation, the 1970s SDP and TDP economies exhibit very similar output and price responses to shocks in Figure 12. The cumulative absolute response 
differences are below $0.03 \%$ in all four cases (see Table 9). To recap, our 1970s DKW economy — with a menu cost distribution calibrated to the 1988-2003 variance decomposition and money growth calibrated to 1970s inflation — looks a lot like a simple TDP economy. The extensive margin contributes little to the variance of aggregate inflation.

We make one final attempt to approximate the effects of 1970s-style inflation on price synchronization. We decompose the variance of inflation over 1988-2003 separately for 250 categories of goods and services. We then compare categories with high and volatile inflation (i.e., both above-average) to categories with low and stable inflation (both below-average). In the "high-mean, high-volatility" group, the medians were $4.3 \%$ and $3.3 \%$ for the mean and standard deviation of inflation, vs. $2.2 \%$ and $1.2 \%$ in the "low-mean, low-volatility" group. The high-high group doesn't reach the 1970s average inflation rate of $6.8 \%$, but more importantly, it exceeds the $2.6 \%$ standard deviation of 1970 s inflation. The median TDP term is modestly lower for the group with high and volatile inflation (96\%) than for the group with low and stable inflation (102\%). This comparison is purely cross-sectional, but it does suggest that higher and more volatile inflation may not produce much more synchronization of price changes.

\section{Conclusions}

We employed micro data from the U.S. Bureau of Labor Statistics to assess the importance of synchronized price changes for fluctuations in CPI inflation from January 1988 through December 2003. We decomposed the variance of inflation over this period into (terms proportional to) the variance of the average size of price changes, the variance of the fraction of items changing price, and the covariance of the two. We found that the variance of 
the average size of price adjustments, by itself, accounted for $95 \%$ of the variance of inflation. When we calibrated the general equilibrium menu cost model of Dotsey, King and Wolman (1999) to fit this empirical variance decomposition, the model produced impulse responses quite close to those in a simple time-dependent model.

Although inflation has been moderate in the U.S. since 1988, this has also been true for most OECD economies. So our results could be relevant for much of the OECD for the recent past and foreseeable future. More difficult to conjecture is whether our results might generalize to periods with higher and more volatile inflation. The availability of more data on individual prices for the U.S. and other countries is needed to answer this question.

Throughout, we used the DKW model because of its tractability. In this model the only source of firm heterogeneity is i.i.d. menu costs across firms and over time, keeping the state-space manageable. But one aspect of the data that the DKW model cannot match is the large absolute size of price changes, which average over $8 \%$ in the BLS micro data. In an environment of low average inflation, such large absolute price adjustments would seem to require sizable idiosyncratic shocks to marginal costs and/or desired markups, as in Golosov and Lucas (2003). Campbell and Eden (2004) find substantial dispersion in new prices of the same product across different grocery stores within cities, consistent with such heterogeneity. But heterogeneous menu costs may be necessary as well, in particular to explain why many price changes are small and why the distribution of price changes is unimodal. Perhaps most promising would be a hybrid model with many sources of heterogeneity, calibrated to fit the 95\% variance decomposition and the entire distribution of price changes. Given the computational difficulty of incorporating such heterogeneity in a dynamic stochastic general equilibrium framework, we leave this for future research. 
Of course, there are alternative theories of price rigidity to the menu costs considered here and in much of the literature. Rotemberg (2002) theorizes that price stickiness comes from customer resistance to price increases they perceive to be unfair. Davis and Hamilton (2004) document sticky wholesale gasoline prices, but reject a menu cost interpretation in favor of strategic motives involving customers and competitors. Burstein (2002) and Mankiw and Reis (2002) explore the implications of sticky plans and sticky information, rather than sticky prices per se. Christiano et al. (2004) and Eichenbaum and Fisher (2004) posit sticky relative prices rather than sticky nominal prices. We argue that any successful theory of sluggish price adjustment should be compatible with our robust finding that there is little synchronization of nominal price changes. 


\section{Appendix: Related statistics provided to Golosov and Lucas (2003).}

To calibrate their model, Golosov and Lucas (2004) use five statistics that we calculated from the BLS CPI Research Database. For all five moments, we used the sample of regular price changes (as defined in our section 2) in New York City and New YorkConnecticut suburbs from January 1988 through December 1997. Let $p_{i j t}$ denote the log price of item $i$ in category $j$ in month $t, \omega_{j}^{93}$ the BLS consumption expenditure weight of $j$, and $\omega_{i j t}$ the BLS weight on item $i$ within category $j$ in month $t$.

The geometric mean inflation rate in month $t$ is

$$
\pi_{t}=\sum_{j} \omega_{j}^{93} \sum_{i} \omega_{i j t}\left(p_{i j t}-p_{i j t-1}\right)
$$

and the associated $\log$ price index is $\bar{p}_{t}=\sum_{s=0}^{t} \pi_{s}$. The first two statistics are the (across time) mean and standard deviation of quarterly inflation, 0.64 and 0.62 percent respectively.

The fraction of items changing price in month $t$ is defined as in the text. The mean fraction for New York areas is 0.219 (the third statistic).

The weighted average price increase is

$$
\sum_{j} \omega_{j}^{93}\left[\sum_{p_{i j t}>p_{i j t-1}} \omega_{i j t}\left(p_{i j t}-p_{i j t-1}\right) / \sum_{p_{i j t}>p_{i j t-1}} \omega_{i j t}\right] .
$$

For the New York areas sample, its mean across time is 0.095 (the fourth statistic). 
Finally, let $z_{i j t}$ be the log deviation of a price from the price index in the category in month $t, z_{i j t}=p_{i j t}-\bar{p}_{j t}$. For each item we calculated the standard deviation of $z_{i j t}$ across months with price increases. We then took the weighted mean of these standard deviations across items and categories:

$$
\sum_{j} \omega_{j}^{93}\left[\sum_{i} \omega_{i j} \operatorname{std}\left(z_{i j t}\right) / \sum_{i} \omega_{i j}\right]
$$

For the New York areas, the average standard deviation of new prices is 0.087 (the fifth statistic). 
Figure 1: A hypothetical sequence of prices for an individual item in the CPI.

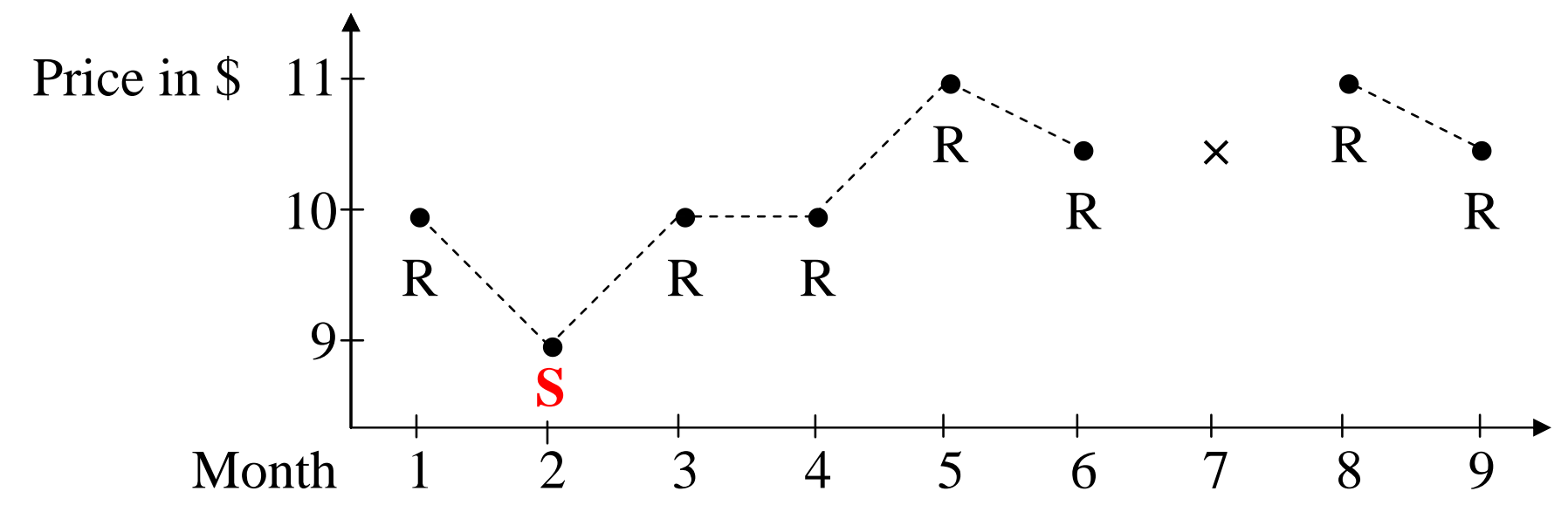

$\begin{array}{rlcccccccc}\text { Price change indicator } & \times & 1 & 1 & 0 & 1 & 1 & \times & 1 & 1 \\ \text { Size of price change (in \%) } & \times & -10 & +10 & \times & +10 & -5 & \times & +5 & -5\end{array}$

$\begin{array}{lllllllllll}\text { Regular price change indicator } & \times & 0 & 0 & 0 & 1 & 1 & \times & 1 & 1\end{array}$ Size of regular price change (in \%) $\quad \times \quad \times \quad \times \quad \times \quad \begin{array}{llllllll}10 & \times & -5 & \times & +5 & -5\end{array}$

$$
\begin{aligned}
& \mathrm{R}=\text { regular price } \\
& \mathrm{S}=\text { sale price }
\end{aligned}
$$


Figure 2

Distribution of Times Between Regular Price Changes

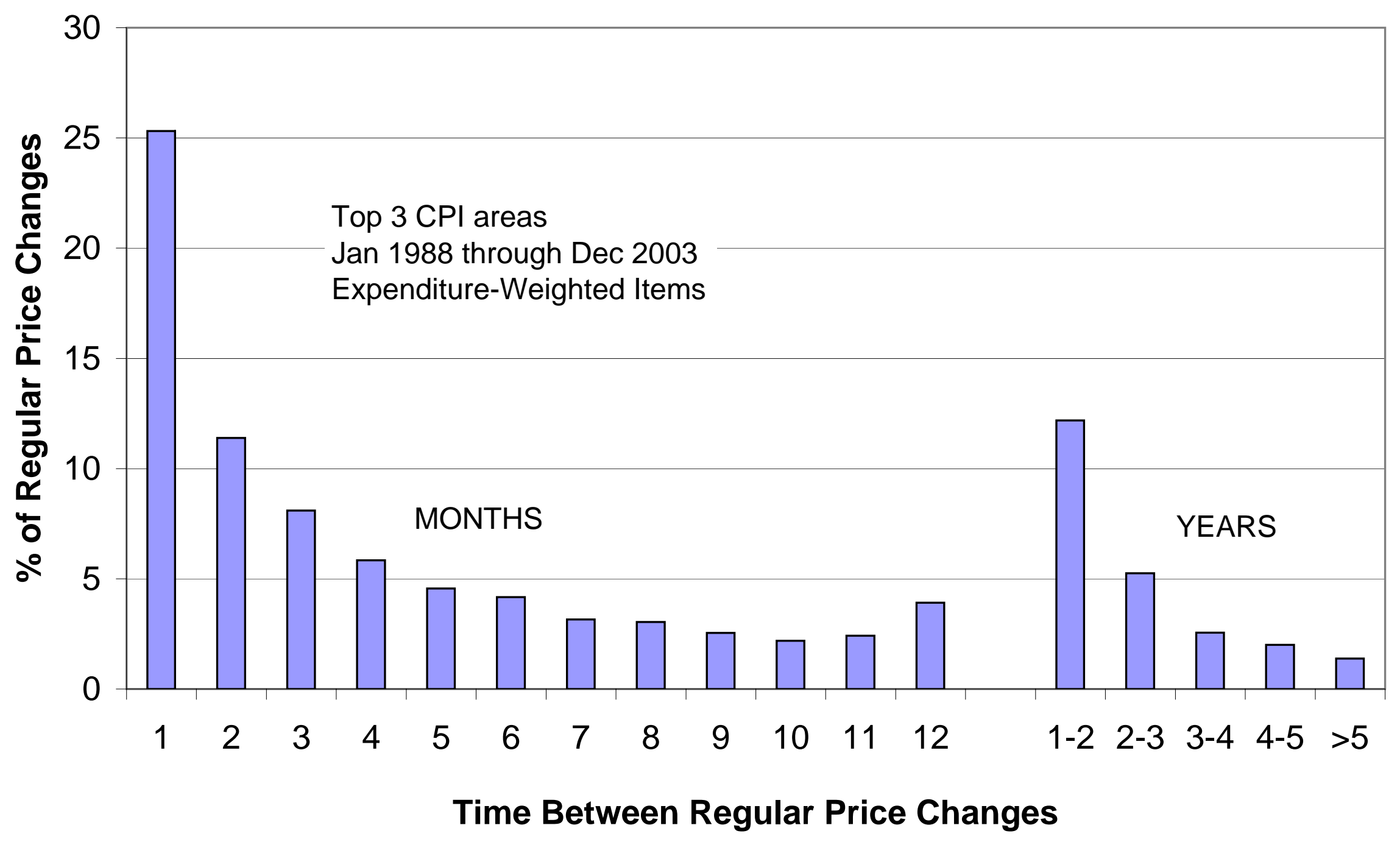


Figure 3

Hazard Rates

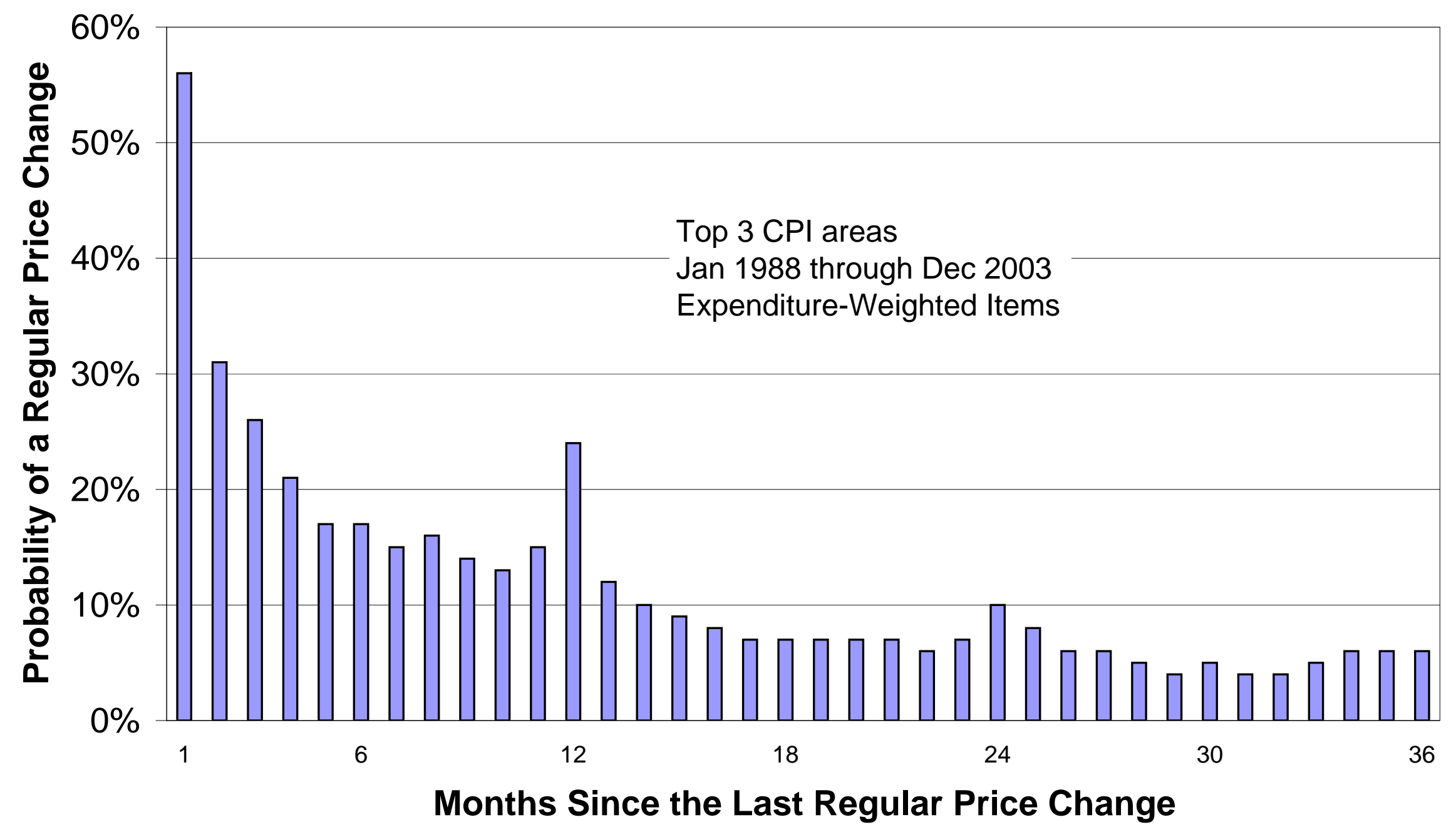


Figure 4

Distribution of Regular Price Changes

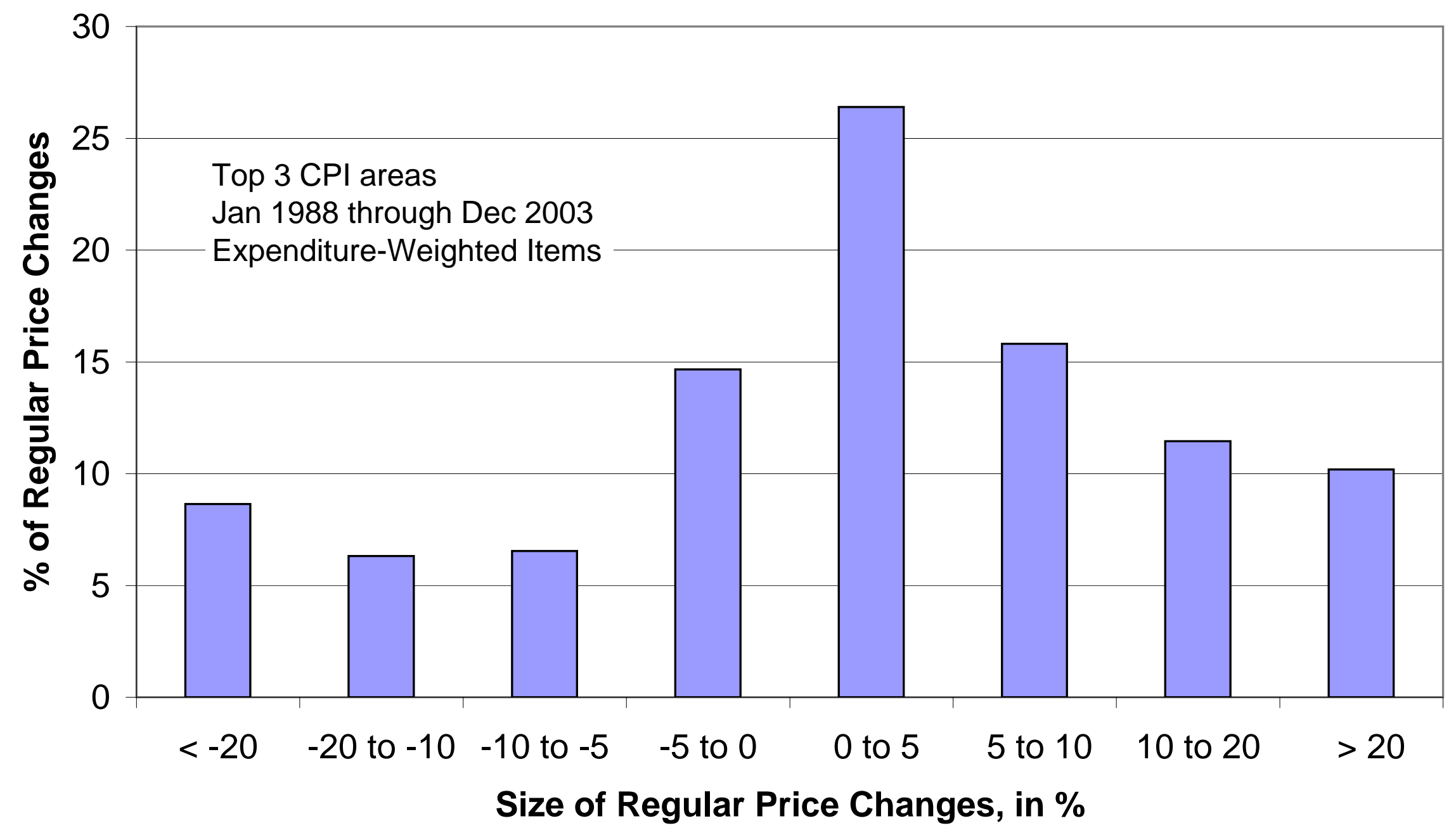


Figure 5

Fraction of prices changing

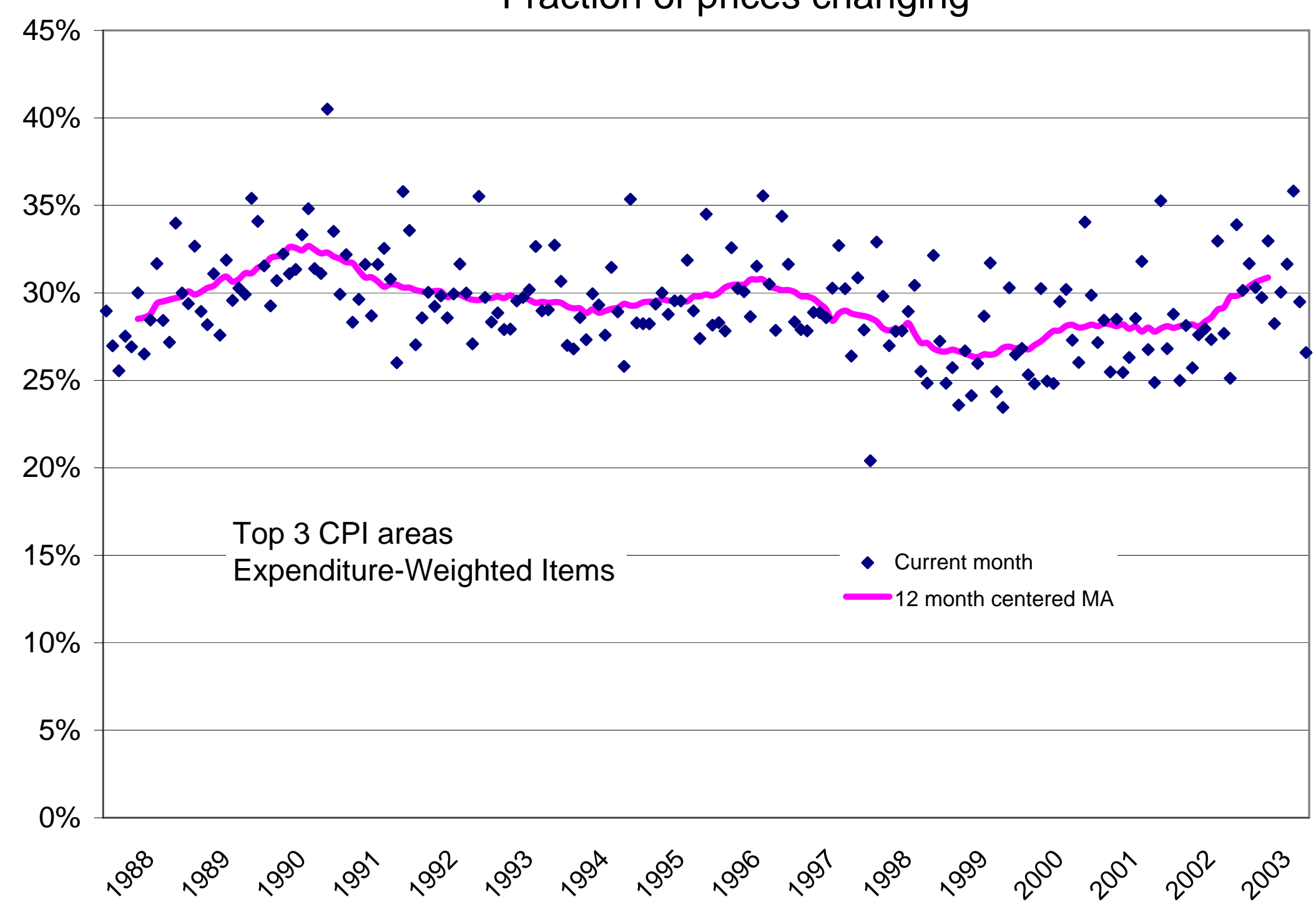


Figure 6

Average size of price changes

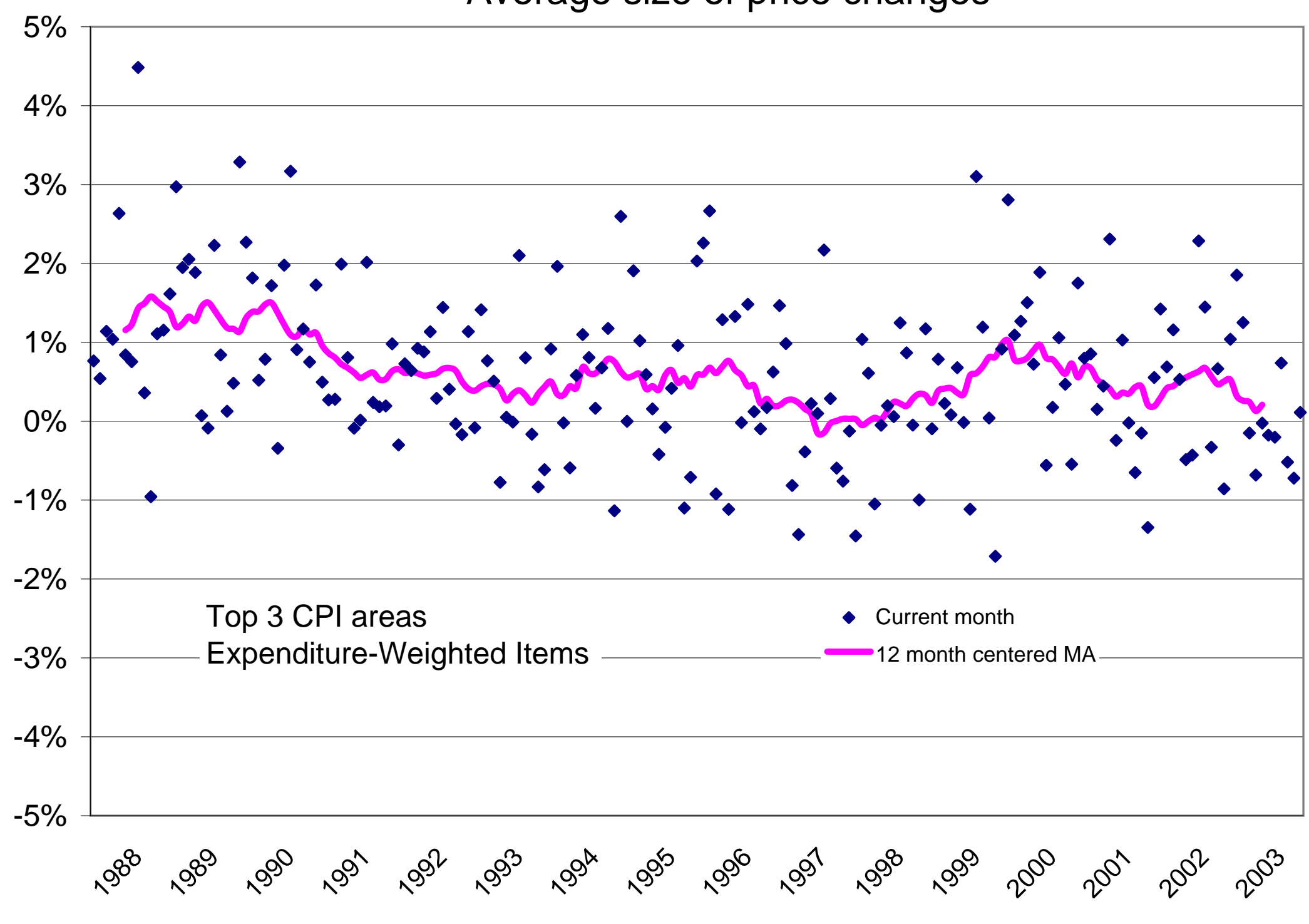


Figure 7

Annual Moving Averages

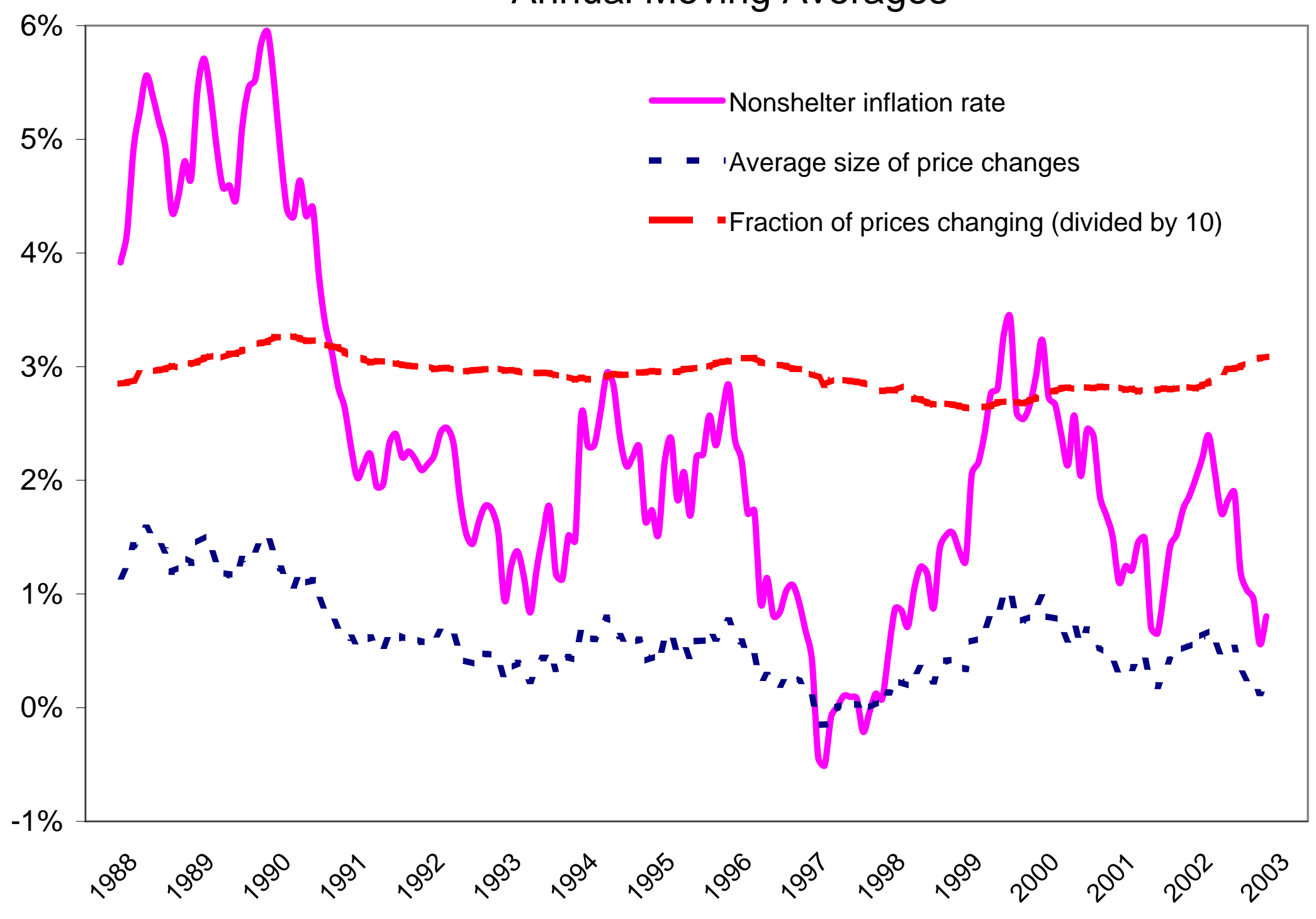


Figure 8: Original Quarterly and Monthly DKW Economies

Responses to a permanent $+1 \%$ money impulse: Quarterly Economy
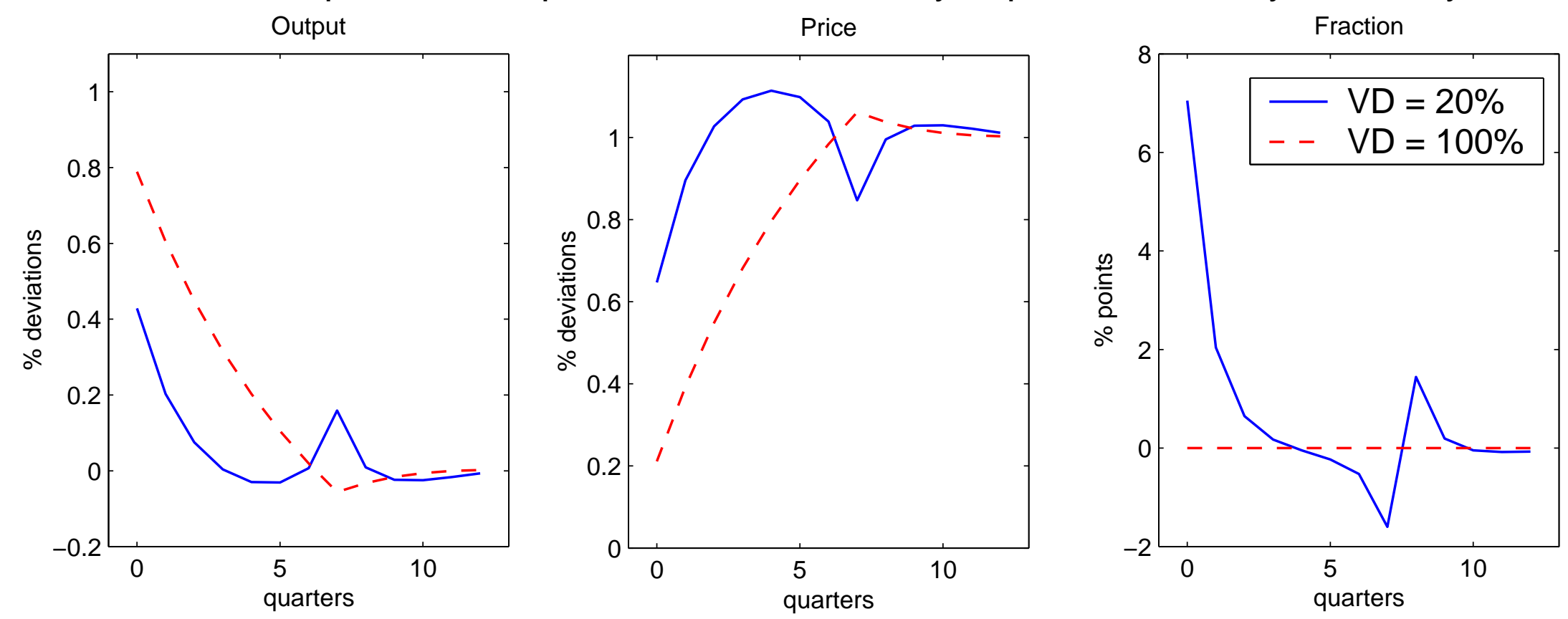

Responses to a permanent $+1 \%$ money impulse: Monthly Economy
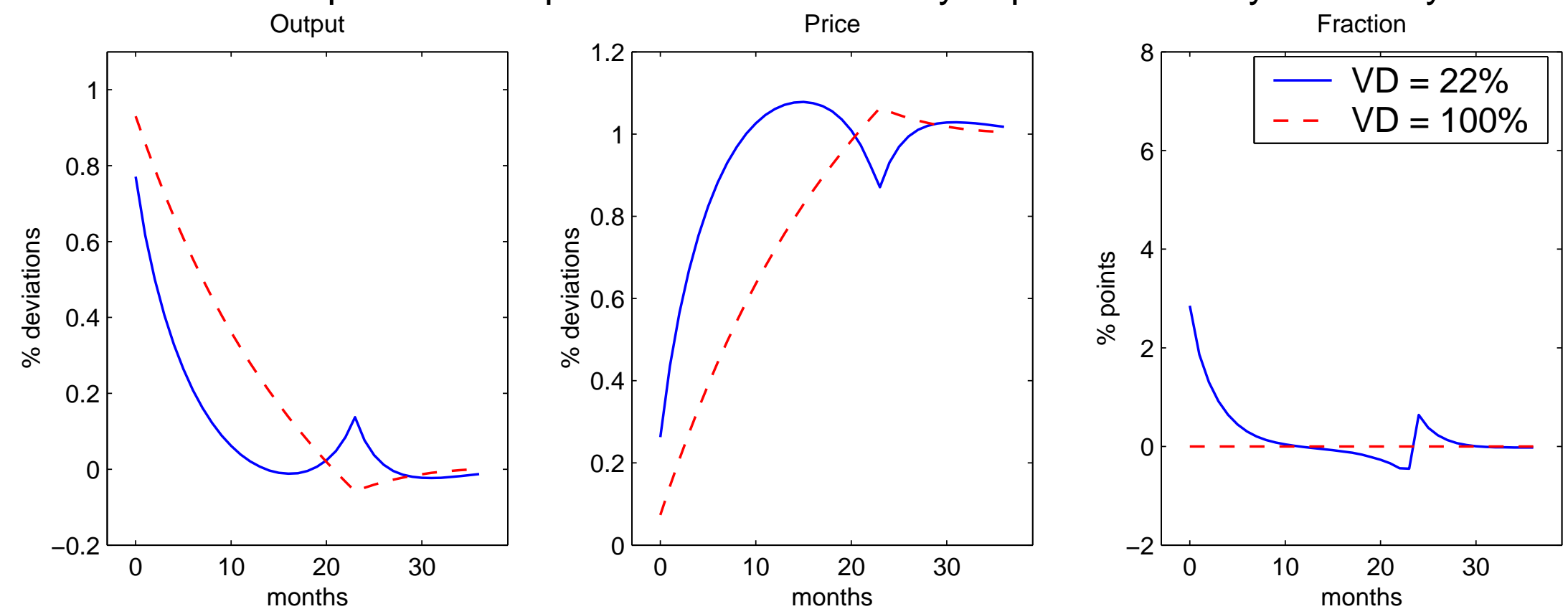
Figure 9

C.D.F. of Fixed Cost, Original Monthly DKW Economy

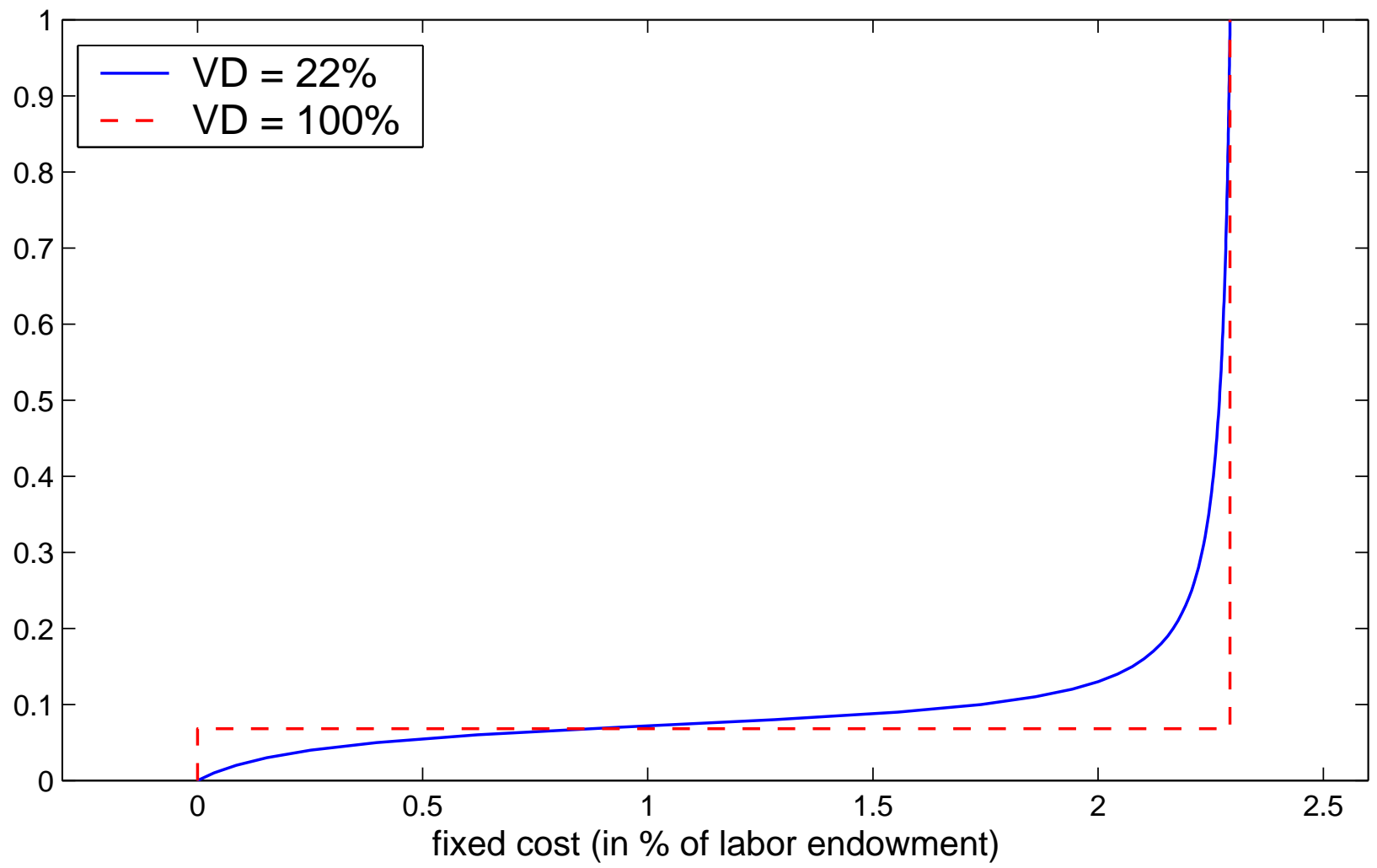

C.D.F. of Fixed Cost, Calibrated DKW Economy

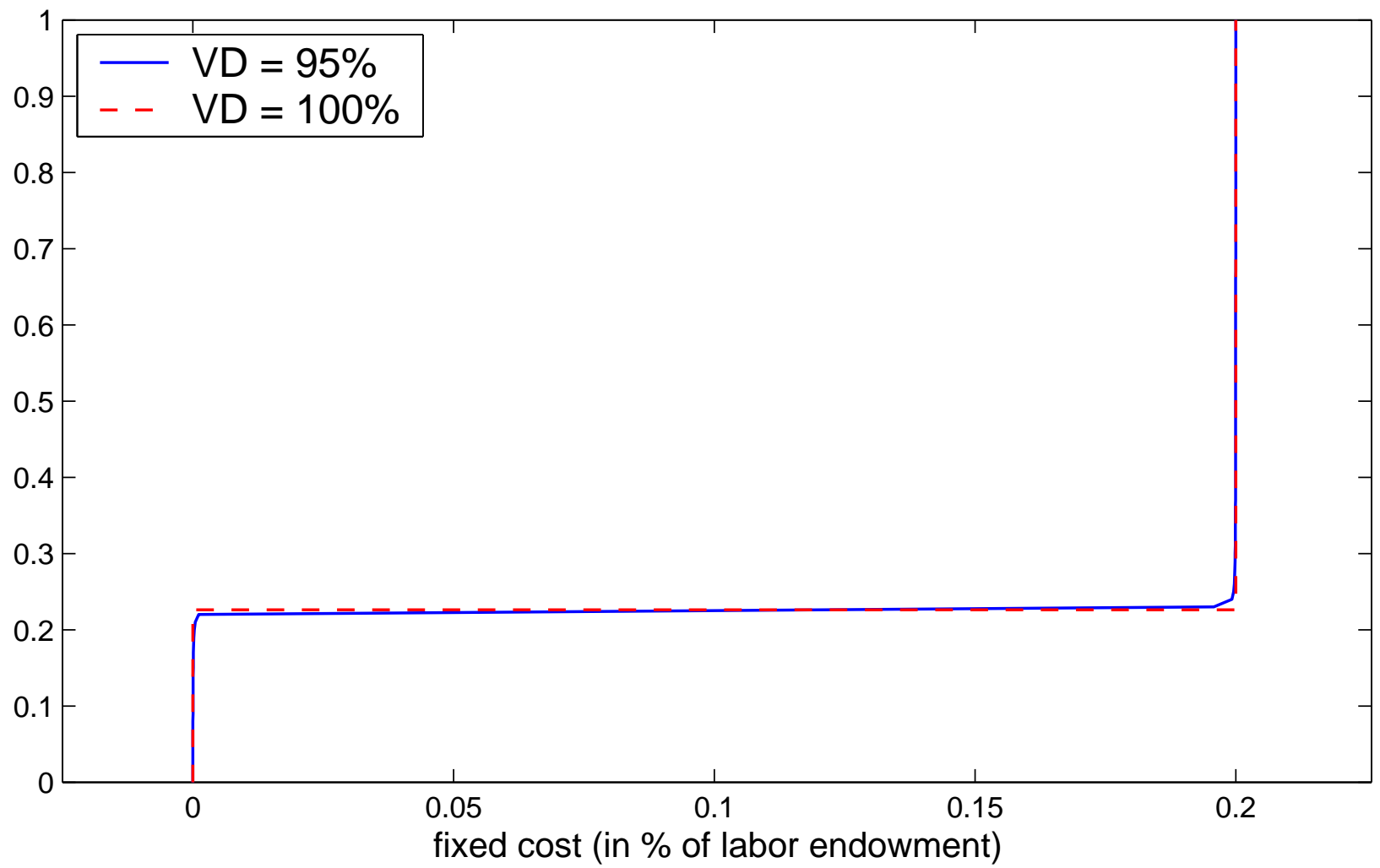




\section{Figure 10: Calibrated DKW Economy}

Responses to a permanent $+1 \%$ money impulse
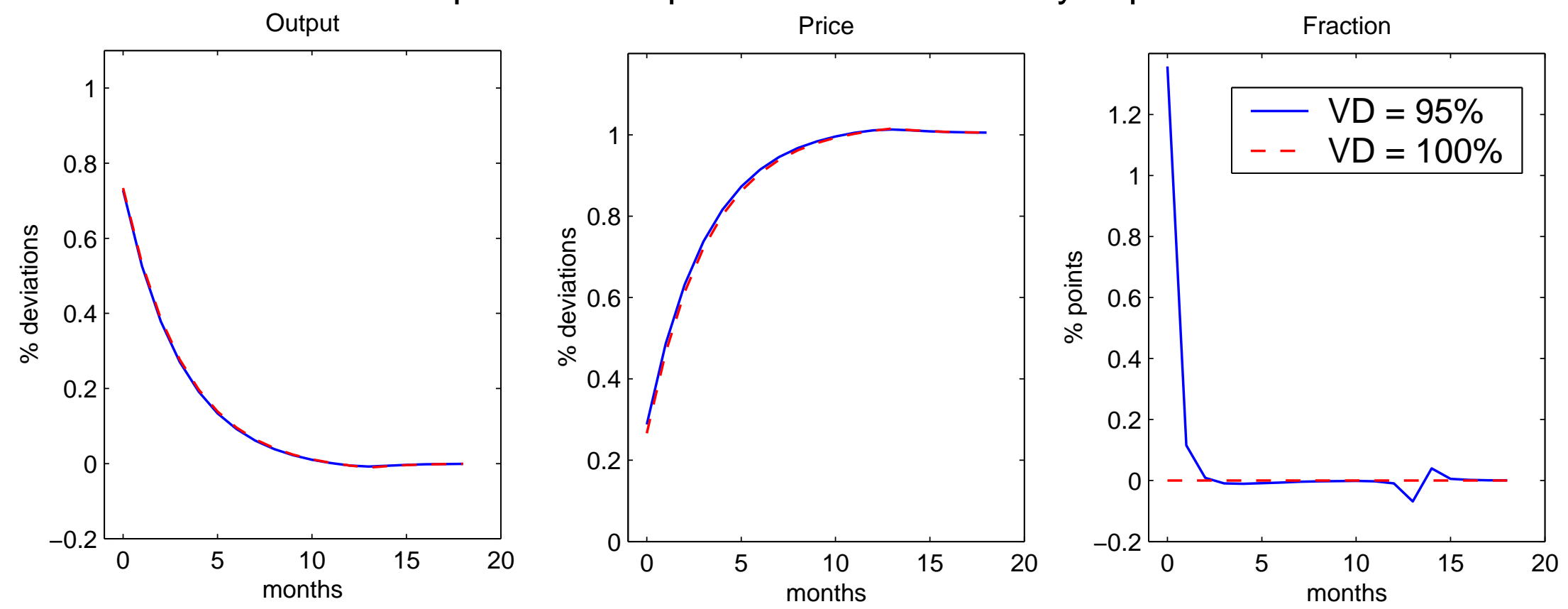

Responses to a permanent $+1 \%$ TFP impulse
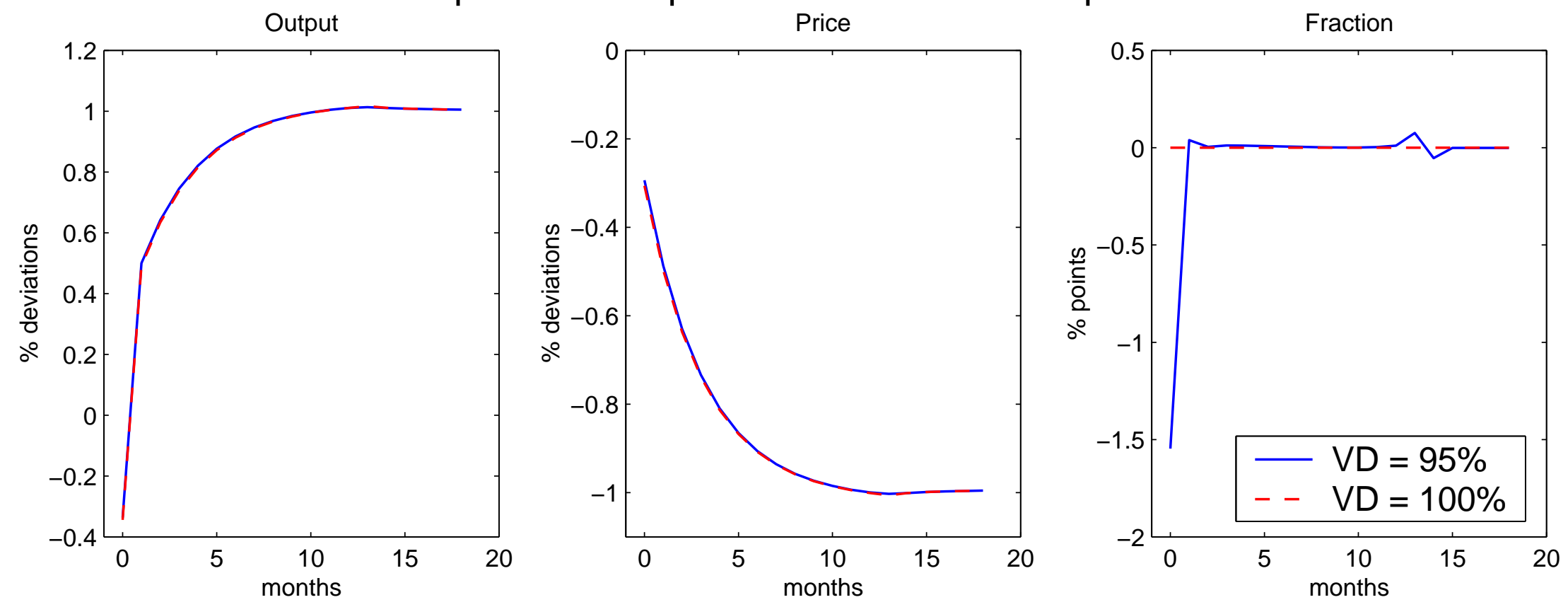


\section{Figure 11}

Conditional adjustment probabilities (hazard rates) in DKW economies

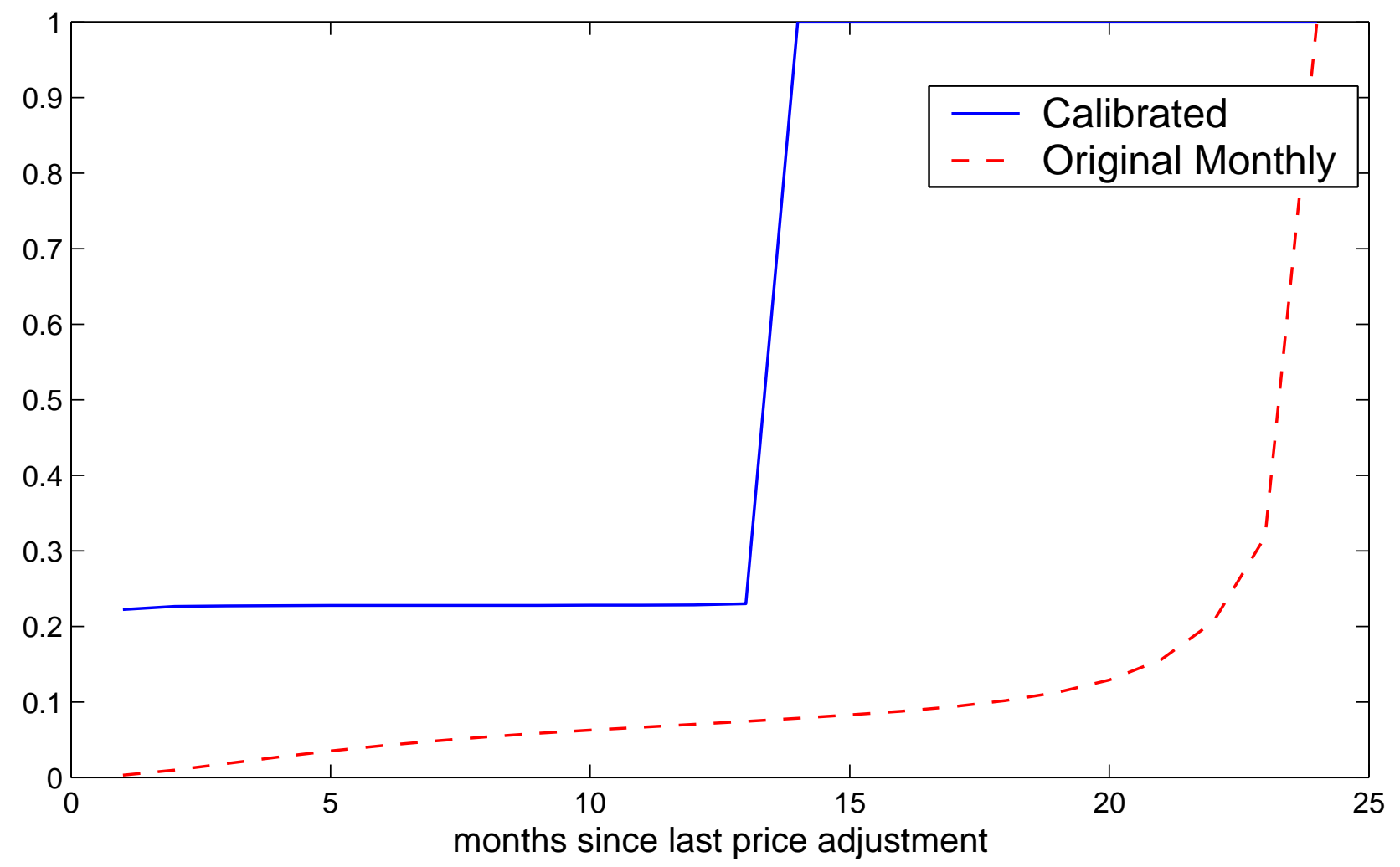

Distribution of firms in DKW economies

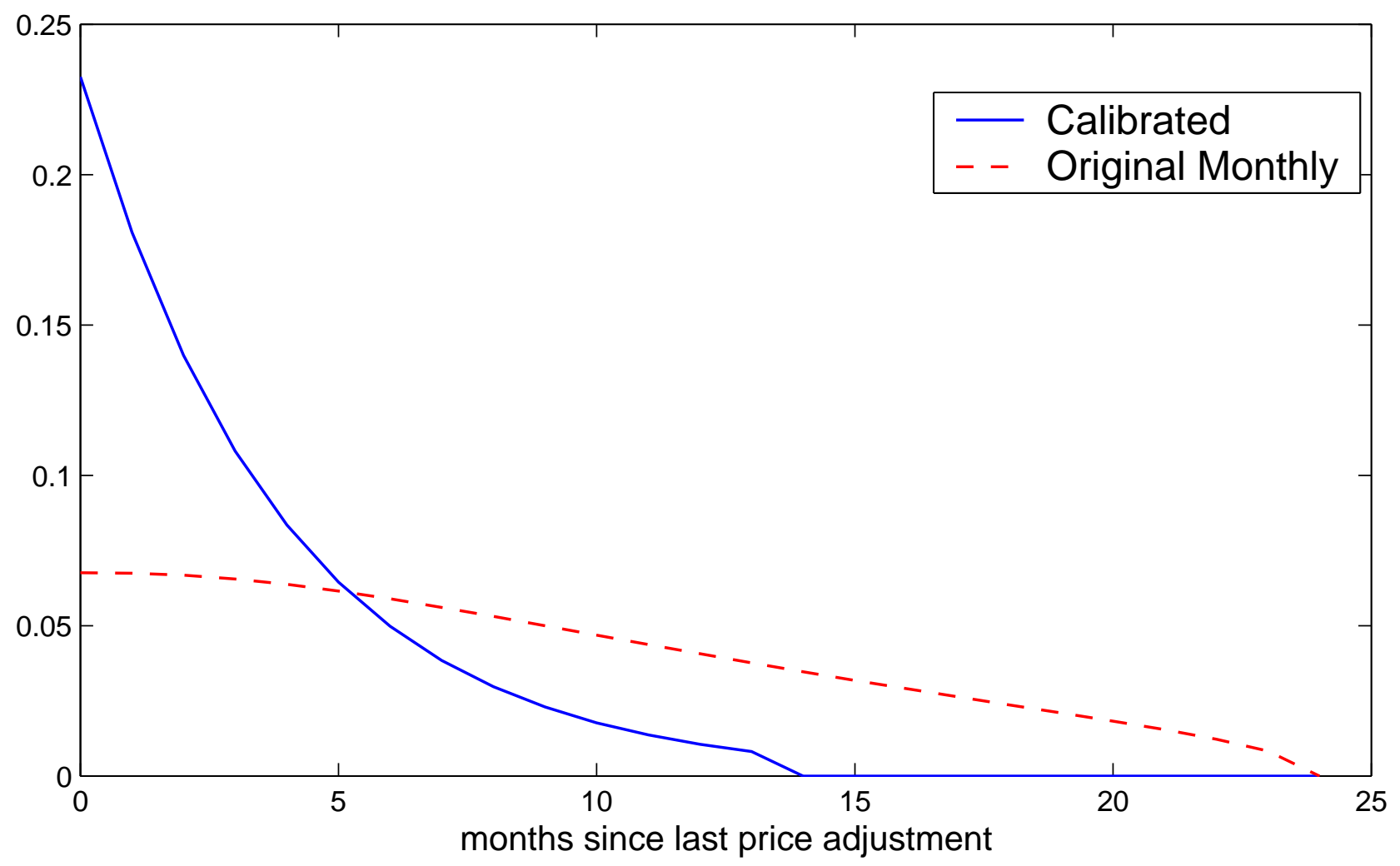




\section{Figure 12: 1970s DKW Economy}
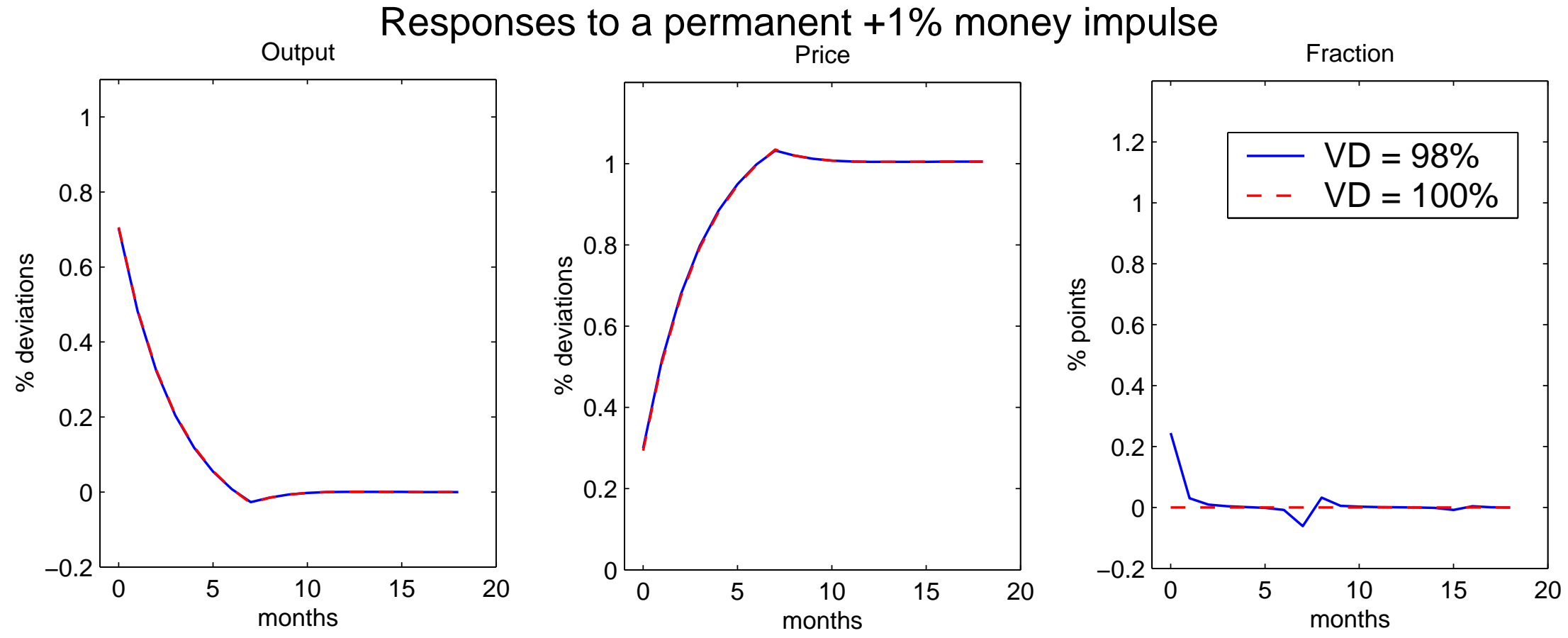

Responses to a permanent $+1 \%$ TFP impulse
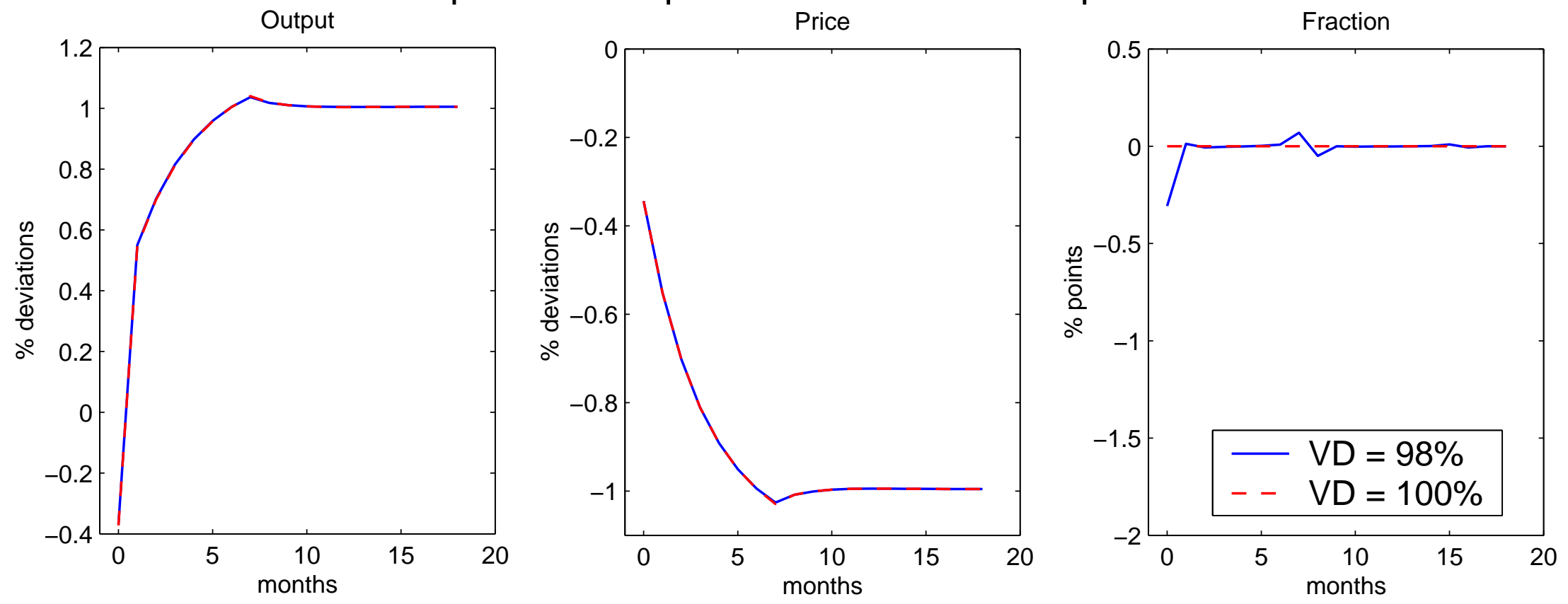


\section{Table 1}

\section{Across-Time Means (and Standard Deviations), in \%}

Sample $\quad \pi \quad f r \quad f r+\quad f r-\quad d p \quad|d p|$

\section{ALL ITEMS}

$\begin{array}{lcccccc}\text { All prices } & 0.19 & 29.3 & 16.1 & 13.2 & 0.61 & 13.3 \\ & (0.31) & (2.9) & (2.5) & (2.1) & (1.04) & (1.3) \\ \text { Regular prices } & 0.26 & 23.3 & 13.4 & 9.9 & 1.11 & 8.5 \\ & (0.28) & (2.8) & (2.6) & (2.1) & (1.14) & (0.95)\end{array}$

\section{CORE ITEMS}

$\begin{array}{lcccccc}\text { All prices } & 0.17 & 26.0 & 14.5 & 11.5 & 0.59 & 13.3 \\ & (0.40) & (3.2) & (2.4) & (2.3) & (1.55) & (1.2) \\ \text { Regular prices } & & & & & & \\ & 0.27 & 20.7 & 12.1 & 8.6 & 1.26 & 8.8 \\ & (0.29) & (3.0) & (2.3) & (2.2) & (1.32) & (1.1)\end{array}$

Notes: Samples run from February 1988 through December 2003 and include data from Top 3 urban areas. All data is from the CPI-RDB. The entries are means and (in parentheses) standard deviations across time of the monthly values of each variable. The monthly values are defined as follows:

$\pi_{t}=$ the weighted mean inflation rate from month $t-1$ to month $t$.

$f r_{t}=$ the weighted mean fraction of items with changing prices from month $t-1$ to month $t$.

$f r+{ }_{t}=$ the weighted mean fraction of items with rising prices from month $t-1$ to month $t$.

$f r-{ }_{t}=$ the weighted mean fraction of items with falling prices from month $t-1$ to month $t$.

$d p_{t}=$ the weighted mean size of price changes from month $t-1$ to month $t$.

$|d p|_{t}=$ the weighted mean absolute size of price changes from month $t-1$ to month $t$.

These monthly values are across-item means. The item means are based on the BLS consumer expenditure surveys and unpublished BLS point-of-purchase surveys. 


\section{Table 2}

\section{Variance Decompositions (using all prices)}

\begin{tabular}{l|c|cc|cr}
\hline \hline \multicolumn{1}{c|}{ Sample } & $\begin{array}{c}\text { Number of } \\
\text { observations } \\
\text { per month }\end{array}$ & TDP term & SDP terms & TDP term & SDP terms \\
\hline \hline TOP 3 AREAS & 14,412 & $97 \%$ & $3 \%$ & $104 \%$ & $-4 \%$ \\
New York & 6,237 & 99 & 1 & 102 & -2 \\
Los Angeles & 4,854 & 94 & 6 & 96 & 4 \\
Chicago & 3,321 & 98 & 2 & 104 & -4 \\
Core Items & 7,105 & 101 & -1 & 111 & -11 \\
\hline
\end{tabular}

Notes: All samples go from February 1988 through December 2003. The number of observations per month includes substitutions. See equation (3) in the text for the definition of the TDP term and the SDP terms. All data is from the CPI-RDB. 


\section{Table 3}

\section{Variance Decompositions (using regular prices)}

\begin{tabular}{l|c|cc|cc}
\hline \hline \multicolumn{1}{c|}{ Sample } & $\begin{array}{c}\text { Number of } \\
\text { observations } \\
\text { per month }\end{array}$ & Including substitutions & \multicolumn{2}{|c}{ Excluding substitutions } \\
\hline \hline TOP 3 AREAS & 14,297 & $91 \%$ & $9 \%$ & $94 \%$ & $6 \%$ \\
New York & 6,188 & 95 & 5 & 96 & 4 \\
Los Angeles & 4,820 & 92 & 8 & 92 & 8 \\
Chicago & 3,289 & 94 & 6 & 96 & 4 \\
Core Items & 7,016 & 88 & 12 & 94 & 6 \\
\hline
\end{tabular}

Notes: All samples go from February 1988 through December 2003. The number of observations per month includes substitutions. See equation (3) in the text for the definition of the TDP term and the SDP terms. All data is from the CPI-RDB. 


\section{Table 4}

\section{Cross-Correlations}

\begin{tabular}{llll}
\hline \hline Sample & Variable & $\pi$ & $\mathrm{Fr}$ \\
& & \\
\hline \hline
\end{tabular}

\section{ALL ITEMS}

$\begin{array}{llll}\text { All prices } & f r & 0.31 & \\ & d p & 0.99 & 0.24 \\ \text { Regular prices } & f r & 0.24 & \\ & d p & 0.98 & 0.11\end{array}$

\section{CORE ITEMS}

$\begin{array}{llll}\text { All prices } & f r & 0.34 & \\ & d p & 0.99 & 0.30 \\ \text { Regular prices } & f r & 0.29 & \\ & d p & 0.98 & 0.17\end{array}$

Notes: Samples run from February 1988 through December 2003 and include data from Top 3 urban areas. All data is from the CPI-RDB. The entries are correlations across time of the monthly values of the variables. The monthly values are defined as follows:

$\pi_{t}=$ the weighted mean inflation rate from month $t-1$ to month $t$.

$f r_{t}=$ the weighted mean fraction of items with changing prices.

$d p_{t}=$ the weighted mean size of price changes.

These monthly values are across-item means. The item means are based on the BLS consumer expenditure surveys and unpublished BLS pointof-purchase surveys. 


\section{Table 5}

\section{DKW Economies Simulated}

DKW Economy

Description

Original Quarterly Original DKW parameter values.

Original Monthly Same parameter values as in "Original Quarterly" except all timerelated parameters are converted to monthly rates.

Calibrated Monthly Same parameter values as in "Original Monthly" except:

Productivity drift and monthly standard deviation are chosen to fit the behavior of quarterly U.S. TFP growth from 1988 through 2002;

Trend money growth and standard deviation are chosen to fit the mean and standard deviation of regular price inflation in the Top 3 areas (regular prices) from Feb 1988 through Dec 2003;

Menu cost distribution parameters are chosen to fit the mean fraction of items changing their regular prices and the 95\% TDP term in the variance decomposition for regular price inflation, both for the Top 3 areas over Feb 1988 through Dec 2003;

the remaining two parameters of the menu cost distribution are chosen so that the minimal menu cost is zero and the maximal menu cost equals $0.2 \%$ of the labor endowment. 


\section{Table 6}

\section{Parameter Values for DKW Economies Simulated}

\begin{tabular}{|c|c|c|c|c|c|}
\hline & & & (A) & (B) & (C) \\
\hline & Parameter & Symbol & $\begin{array}{l}\text { Original } \\
\text { Quarterly }\end{array}$ & $\begin{array}{l}\text { Original } \\
\text { Monthly }\end{array}$ & $\begin{array}{c}\text { Calibrated } \\
\text { Monthly }\end{array}$ \\
\hline \multirow[t]{4}{*}{ Preferences } & Annualized discount rate & $R$ & $6.5 \%$ & Same & Same \\
\hline & Risk aversion & $\sigma$ & 1 & Same & Same \\
\hline & Interest elasticity & $\eta$ & 0 & Same & Same \\
\hline & Labor supply elasticity & $-(1-l) /(l \xi)$ & $-\infty$ & Same & Same \\
\hline \multirow[t]{2}{*}{ Technology } & Capital share & $\alpha$ & $1 / 3$ & Same & Same \\
\hline & Markup & $1 / \theta$ & 1.3 & Same & Same \\
\hline \multirow[t]{11}{*}{ Shocks } & Money growth: & & & & \\
\hline & Annualized mean & $\mu_{m}$ & $5.0 \%$ & Same & $4.8 \%$ \\
\hline & Serial correlation & $\rho_{m}$ & 0 & Same & Same \\
\hline & Error standard deviation & $\sigma_{m}$ & $1.0 \%$ & Same & $0.6 \%$ \\
\hline & Productivity growth: & & & & \\
\hline & Annualized mean & $\mu_{a}$ & N/A & $\mathrm{N} / \mathrm{A}$ & $1.5 \%$ \\
\hline & Error standard deviation & $\sigma_{a}$ & N/A & $\mathrm{N} / \mathrm{A}$ & $0.4 \%$ \\
\hline & Menu cost & $c_{1}$ & 0.1964 & 0.0727 & 0.2278 \\
\hline & & $c_{2}$ & 0.0625 & 0.0231 & 0.0001 \\
\hline & & $c_{3}$ & 367.44 & 367.44 & 1570.4 \\
\hline & & $c_{4}$ & 1.2626 & 1.2626 & 1.5702 \\
\hline
\end{tabular}

Note: In all three economies the weight on leisure $\psi$ is such that the steady state labor supply is $20 \%$ of labor endowment. 


\section{Table 7}

\section{Simulations of DKW Economies}

(A)

(B)

(C)

DKW Economy

\# of cohorts, $J$

Mean fraction of prices changing

Cumulative Absolute Response Differences...

... after a monetary shock:

Output

Price

... after a productivity shock:

Output

Price

Variance Decomposition of Inflation:
Original

Quarterly
Original

Monthly
14

$\begin{array}{ccc}8 & 24 & 14 \\ 20 \% & 6.7 \% & 23 \%\end{array}$

$6.5 \%$

$8.3 \%$

$5.6 \%$

$7.2 \%$

$0.1 \%$

$0.1 \%$

\section{$7.2 \%$}

$5.1 \%$

$5.8 \%$

$4.4 \%$

$0.1 \%$

$0.1 \%$
Calibrated

Monthly
$20 \%$

$80 \%$
$22 \%$

$78 \%$
$95 \%$ $5 \%$

Notes: Means are across 100 simulations. Each simulation consists of equilibrium responses to stochastic disturbances for 63 periods in the quarterly model and 191 periods in the monthly model. Equation (3) in the text, reproduced here, presents the exact variance decomposition for inflation:

$$
\operatorname{var}\left(\pi_{t}\right)=\underbrace{{\overline{f r_{t}}}^{2} \cdot \operatorname{var}\left(d p_{t}\right)}_{\text {TDP term }}+\underbrace{\operatorname{var}\left(f r_{t} \cdot \overline{d p_{t}}+\left(d p_{t}-\overline{d p_{t}}\right) \cdot\left(f r_{t}-\overline{f r_{t}}\right)\right)+2 \operatorname{cov}_{t}}_{\text {SDP terms }} .
$$




\section{Table 8}

\section{Correlations for DKW Economies vs. Data}

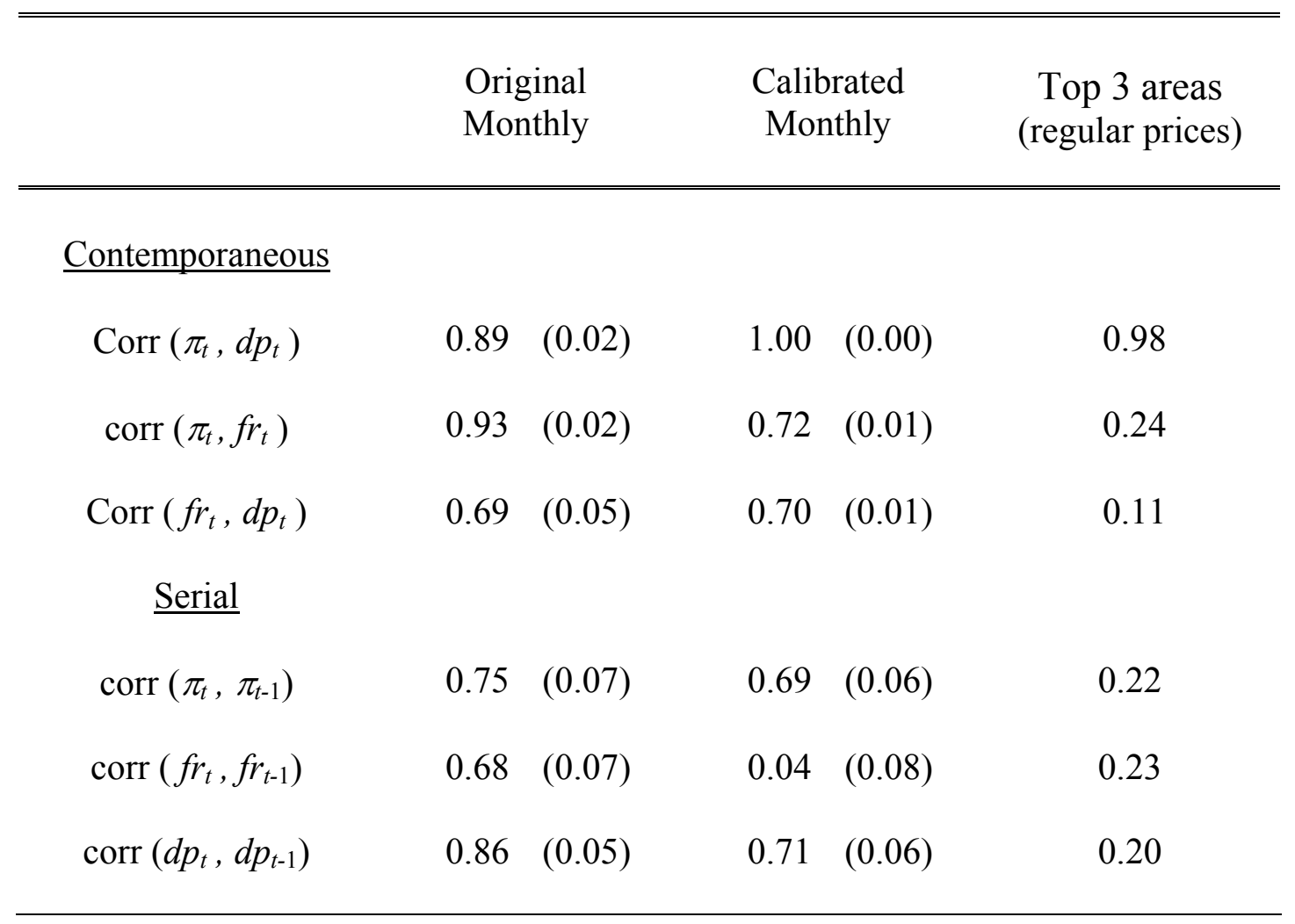

Notes: For the model economies we report mean values across 100 simulations (and standard deviations across simulations in parentheses). Each simulation consists of equilibrium responses to stochastic disturbances for 191 months. The Top 3 area data spans the 191 months from February 1988 through December 2003. 


\section{Table 9}

\section{Simulations of a 1970s DKW Economy}

\# of cohorts, $\mathrm{J}$

Cumulative Absolute Response Differences ...

... after a monetary shock:

Output

Price

... after a productivity shock:

Output

Price

Variance Decomposition of Inflation:

TDP term

SDP terms
8

$0.02 \%$

$0.03 \%$

$0.02 \%$

$0.01 \%$

$98 \%$

$2 \%$

Notes: All parameters are from the Calibrated Monthly DKW economy except for trend and standard deviation of the money growth, which are chosen to match the proportionately higher mean and standard deviation of monthly CPI inflation from January 1970 through December 1979. Means are across 100 simulations (and standard deviations across simulations are in parentheses). Each simulation consists of equilibrium responses to stochastic disturbances for 120 months. 


\section{References}

Bils, Mark and Peter J. Klenow (2004), "Some Evidence on the Importance of Sticky Prices," Journal of Political Economy 112 (October), 947-985.

Burstein, Ariel (2002), "Inflation and Output Dynamics with State Dependent Pricing Decisions," unpublished paper, UCLA.

Caballero, Ricardo and Eduardo Engel (1993), "Heterogeneity and Output Fluctuations in a Dynamic Menu-Cost Economy,” Review of Economic Studies 60 (January), 95-119.

Calvo, Guillermo A. (1983), "Staggered Prices in a Utility-Maximizing Framework," Journal of Monetary Economics 12 (September), 383-398.

Campbell, Jeffrey R. and Benjamin Eden (2004), "Rigid Prices: Evidence from U.S. Scanner Data," unpublished paper, Federal Reserve Bank of Chicago.

Caplin, Andrew and John Leahy (1991), "State-Dependent Pricing and the Dynamics of Money and Output,” Quarterly Journal of Economics 106 (August), 683-708.

Caplin, Andrew and John Leahy (1997), "Aggregation and Optimization with StateDependent Pricing," Econometrica 65 (May), 601-625.

Caplin, Andrew and Daniel Spulber (1987), "Menu Costs and the Neutrality of Money," Quarterly Journal of Economics 102 (November), 703-725.

Cecchetti, Stephen G. (1985), "Staggered Contracts and the Frequency of Price Adjustment," Quarterly Journal of Economics 100 (Supplement), 935-959.

Cecchetti, Stephen G. (1987), "Indexation and Incomes Policy: A Study of Wage Adjustments in Unionized Manufacturing,” Journal of Labor Economics 5 (July), 391-412.

Chari, V.V, Patrick J. Kehoe, and Ellen R. McGrattan (2000), "Sticky Price Models of the Business Cycle," Econometrica 68 (September), 1151-1180.

Chevalier, Judith A., Anil K. Kashyap, and Peter E. Rossi (2003), "Why Don't Prices Rise During Periods of Peak Demand? Evidence from Scanner Data," American Economic Review 93 (March), 15-37.

Christiano, Lawrence J., Martin Eichenbaum, and Charles Evans (2004), "Nominal Rigidities and the Dynamic Effects of a Shock to Monetary Policy," forthcoming in the Journal of Political Economy 112 (December).

Davis, Michael C. and James D. Hamilton (2004), "Why Are Prices Sticky? The Dynamics of Wholesale Gasoline Prices,” Journal of Money, Credit, and Banking 36 (February), $17-37$. 
Dotsey, Michael, Robert King and Alexander Wolman (1999), "State-Dependent Pricing and the General Equilibrium Dynamics of Money and Output," Quarterly Journal of Economics 114 (May), 655-690.

Eichenbaum, Martin and Jonas Fisher (2004), "Evaluating the Calvo Model of Sticky Prices," NBER Working Paper 10617 (January).

Golosov, Mikhail and Robert E. Lucas, Jr. (2003), "Menu Costs and Phillips Curves," NBER Working Paper 10187 (December).

Mankiw, Gregory N. and Ricardo Reis (2002), "Sticky Information Versus Sticky Prices: A Proposal to Replace the New Keynesian Phillips Curve," Quarterly Journal of Economics 117 (November), 1295-1328.

Rotemberg, Julio J. (2002), “Customer Anger at Price Increases, Time Variation in the Frequency of Price Changes and Monetary Policy,” NBER Working Paper 9320 (November).

Taylor, John B. (1980), “Aggregate Dynamics and Staggered Contracts,” Journal of Political Economy 88 (February), 1-23.

U.S. Department of Labor (1997), BLS Handbook of Methods, Bulletin 2490, U.S. Government Printing Office.

Willis, Jonathan (2000), "General Equilibrium of a Monetary Model with State-Dependent Pricing," unpublished paper, Federal Reserve Bank of Kansas City.

Wolman, Alexander (1999), "Sticky Prices, Marginal Cost, and the Behavior of Inflation," Federal Reserve Bank of Richmond Economic Quarterly 85 (Fall), 29-48. 